\title{
Optimal Integrated Energy Systems Design incorporating Variable Renewable Energy Sources
}

\author{
Oluwamayowa O. Amusat ${ }^{\mathrm{a}}$, Paul R. Shearing ${ }^{\mathrm{b}}$, Eric S. Fraga, ${ }^{\mathrm{a}, *}$ \\ ${ }^{a}$ Centre for Process Systems Engineering, Department of Chemical Engineering, University College London, Torrington \\ Place, London WC1E 7JE, United Kingdom \\ ${ }^{b}$ Electrochemical Innovation Lab, Department of Chemical Engineering, University College London, Torrington Place, \\ London WC1E 7JE, United Kingdom
}

\begin{abstract}
The effect of variability in renewable input sources on the optimal design and reliability of an integrated energy system designed for off-grid mining operation is investigated via a two-stage approach. Firstly, possible energy system designs are generated by solving a deterministic non-linear programming (NLP) optimization problem to minimize the capital cost for a number of input scenarios. Two measures of reliability, the loss of power supply probability (LPSP) and energy index of reliability (EIR), are then evaluated for each design based on the minimization of the external energy required to satisfy load demands under a variety of input conditions. Two case studies of mining operations located in regions with different degrees of variability are presented. The results show that the degree of variability has an impact on the design configuration, cost and performance, and highlights the limitations associated with deterministic decision making for high variability systems.
\end{abstract}

Keywords: Energy storage, power generation, reliability, renewables variability, systems design

\footnotetext{
* Corresponding author

Email addresses: oluwamayowa.amusat.13@ucl.ac.uk (Oluwamayowa O. Amusat), p.shearing@ucl.ac.uk (Paul R. Shearing), e.fraga@ucl.ac.uk (Eric S. Fraga)
} 
for representing renewables variability. The first approach is chronological simulation, in which variability is represented using time-series data. This method takes into account variability within a given time period (usually a year). This approach is computationally burdensome (Yang et al., 2009) and requires the availability of historical data. This is the most commonly used approach and has been applied extensively to PV-wind-battery systems (Yang et al., 2008; Diaf et al., 2008; Al-Shamma'a and Addoweesh, 2014; Kaabeche and Ibtiouen, 2014). The second approach uses probabilistic techniques to incorporate the stochastic nature of the renewable resource, thus eliminating the need for time-series data. Tina et al. (2006) applied an analytical approach based on the convolution technique to the design of a hybrid wind-PV system, with probability density functions used in the representation of variability. Gooding et al. (2014) also adopted a probabilistic approach to modelling variability for energy systems design, with several operating states defined in order to determine the system reliability. A similar modelling approach was also used by ElDesouky (2014), where a PV-wind-thermal generation scheduling problem was solved by using an adaptive hybrid technique combining a genetic algorithm (GA) and an artificial neural network (ANN). However, this approach cannot account for the dynamic changing performance of the hybrid energy system (Chauhan and Saini, 2014). Thus, works involving energy storage dynamics are based on chronological simulation.

While these and several works account for daily and seasonal variability in the optimal design of hybrid $\mathrm{PV} /$ wind/storage systems, all consider fixed renewable input conditions, with system reliability defined in terms of demand satisfaction under deterministic input conditions. They do not account for the stochastic nature of renewables input and how it may affect the performance of any generated designs. Also, no consideration has been given to integrated energy systems which incorporate solar-thermal as a potential generation alternative. The effect of variability on the sizing of systems integrating multiple large scale energy storage options also needs to be considered.

The purpose of this work is to investigate the effect of variability in renewable input conditions on the optimal design and performance of integrated energy systems incorporating both thermal and electrical generation as well as large-scale storage, and is based on the combination of alternatives presented in Amusat et al. (2015b). This will be achieved by comparing the range of optimal designs obtained for two case studies with different degrees of variability in renewable input.

\section{Reliability Modelling}

One of the major challenges associated with renewable energy use is the variable nature of the resource, with availability changing within and between seasons. Design of renewable energy systems without taking into account the stochastic nature of the resource generates systems which, while optimal for the scenario for which they are designed, may perform sub-optimally under other possible input scenarios. However, accounting for the variability increases the complexity of design for integrated energy systems.

The need to characterize the performance of power systems leads to the concept of reliability. According to Osborn and Kawann (2001), reliability refers to "the ability of power system components to deliver electricity to all points of consumption, in the quantity and with the quality demanded by the customer". It is a measure of the frequency, duration and extent to which a power system experiences failure (i.e. unable to satisfy demand) and therefore provides a basis on which the performance of different types of energy systems may be compared.

Several measures have been used in literature to represent reliability in renewable energy systems (Tina et al., 2006; Dufo-Lopez and Bernal-Agustin, 2008; Diaf et al., 2008; Yang et al., 2009; Al-Shamma'a and Addoweesh, 2014; Chauhan and Saini, 2014). However, the most frequently used measure of reliability is the loss of power supply probability, LPSP (Diaf et al., 2008; Yang et al., 2009; Ould Bilal et al., 2010; AlShamma'a and Addoweesh, 2014). LPSP is the probability that insufficient energy supply occurs when the hybrid system is unable to satisfy the load demand (Yang et al., 2003). It represents the fraction of operation time in which the energy supplied by the energy system $P_{\text {supplied }}$ will be insufficient to meet demand $P_{\text {demand }}$ and may be written as (Yang et al., 2009)

$$
L P S P=\frac{\sum_{t=1}^{T} \text { Power failure time }\left(P_{\text {supplied }}(t)<P_{\text {demand }}(t)\right)}{\text { Total time period of operation, } T}
$$


LPSP has been considered both as a constraint to be satisfied in single-objective design (Yang et al., 2007, 2009; Al-Shamma'a and Addoweesh, 2014) and as one of the objectives in multi-criteria design (Diaf et al., 2008; Ould Bilal et al., 2010; Abbes et al., 2014).

Another reliability measure often used in energy systems design is the expected energy not supplied (EENS). EENS refers to the amount of energy not supplied by the power system when the load exceeds available generation (Tina et al., 2006),

$$
\text { EENS }=\sum_{t=1}^{T}\left(P_{\text {demand }}(t)-P_{\text {supplied }}(t)\right)
$$

EENS is a measure of the extent of failure of the energy system. Dufo-Lopez and Bernal-Agustin (2008) treated the unmet load as one of three objectives in the design of a PV-wind-diesel hybrid system.

The energy index of reliability (EIR) is the fraction of the demand satisfied by an energy system and is directly related to EENS (Tina et al., 2006),

$$
E I R=1-\frac{E E N S}{\sum_{t=1}^{T} P_{\text {demand }}(t)}
$$

The EIR was treated as the sole objective in the design of a stand-alone PV-wind system by Tina et al. (2006).

These (and other) reliability measures have been used to investigate the performance of possible renewable energy systems under fixed renewable input scenarios. Single time periods of operation between one day $(24 \mathrm{~h})$ and one year $(8760 \mathrm{~h})$ have been considered, thus incorporating information about diurnal and/or seasonal variability in the optimization process and providing information on reliability within the specified time periods. In this work, we extend these reliability measures to investigate the effect of variability in renewables input conditions on the design process.

We consider the response of given energy system designs, each identified as optimal (fully reliable) under specific input conditions, to variations in the input solar radiation. Designs generated under deterministic conditions are evaluated over a wide range of possible input conditions to account for stochasticity, thus obtaining measures of the reliability of each design. To do this, we need to modify the reliability measures. The loss of power probability is modified to consider the effect of variability in inputs by treating each renewable input scenario as a single time step. Thus, the loss of power probability refers to the fraction of operational scenarios in which energy supply from the energy system will not satisfy the total demands of the plant,

$$
L P S P=\frac{\sum_{\text {eval }}^{N_{\text {en }}} \text { Power failure scenarios }\left(\sum_{t=1}^{T}\left[P_{\text {supplied }}(t)-P_{\text {demand }}(t)\right]>0\right)}{\text { Total number of renewable input scenarios, } N_{\text {eval }}}
$$

By this definition, a design with LPSP $=0.2$ will fail to meet load demands in $20 \%$ of renewable input cases. The left hand side of the term in the bracket of Equation 4 gives the total external energy that will need to be supplied externally if the plant load is to be satisfied.

The EENS is modified by considering the probability-weighted average of the total energy shortfalls from the individual evaluation scenarios. Thus, for $z$ scenarios, the average EENS for any design is given by

$$
E E N S=\sum_{z} w_{z} \cdot E E N S_{z}
$$

where $w_{z}$ is the probability-based weight attached to scenario $z$ occuring,

$$
\sum_{z=1}^{N_{\text {eval }}} w_{z}=1
$$

The EENS indicates, on the average, how much energy will not be supplied by the renewables system. 


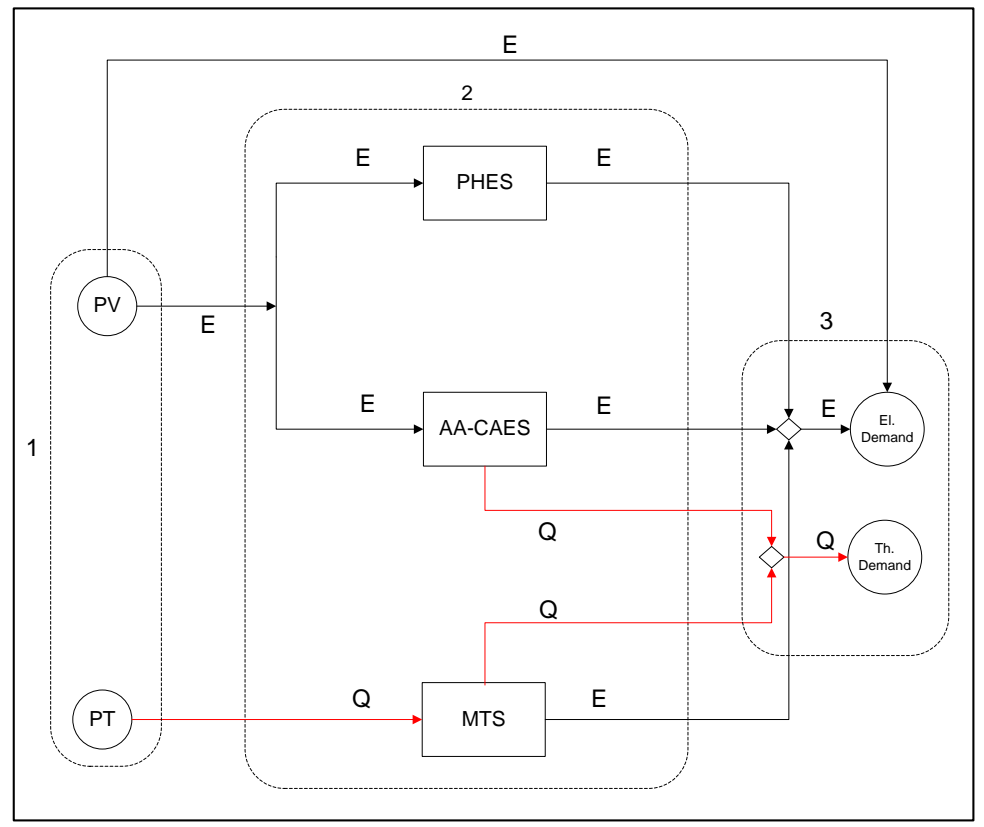

Figure 1: Proposed energy superstructure. The numbered system boxes (represented with dashed lines) show the three main parts of the energy system: generation (1), storage (2) and demand satisfaction (3). The black lines (labelled E) represent electricity, while the red lines (labelled Q) represent heat.

Based on these reliability measures, comparisons of designs may be made both in terms of cost and performance. Incorporating both measures of reliability allows us to be able to study the effect of variability both quantitatively (how often a design fails between scenarios) and qualitatively (to what degree the design fails within scenarios). In order to avoid confusion, the LPSP is often referred to as as a measure of reliability of the designs while the EIR and EENS are referred to as a measure of performance.

To be able to evaluate these reliability measures, a model of the energy system under consideration is required. The next section will focus on describing the energy system and defining the design problem to be solved. Section 4 then presents the relevant energy system models, including how the reliability metrics are evaluated.

\section{Problem Description}

We investigate the effect of variability on energy systems by comparing the cost and performance of alternative configurations of an energy system integrating multiple renewable generation and storage options as shown in Figure 1.

Two solar energy generation options are considered: photovoltaic (PV) cells and power towers (PT). The photovoltaic system consists of two components: solar panels, which generate electricity in the form of direct current, and power-point tracking inverter(s) which convert from direct to alternating current. Solar towers collect energy in the form of heat in molten salts, with the hot salt then used for electricity generation through heating of steam for a turbine.

Two options are considered for electrical energy storage: Pumped Hydraulic Energy Storage (PHES) and Advanced Adiabatic Compressed Air Storage (AA-CAES). A third option, molten tank storage (MTS), stores thermal energy. The storage alternatives are fundamentally different in use and losses. The PHES system generates only electricity and incurs use-dependent losses. The AA-CAES system can supply both heat and electricity but incurs hourly (thermal) losses. Together, these options should be able to cater for the requirements of the process.

The integrated energy system allows for the electrical demands to be met directly from the PV system or from any of the storage options, while the thermal demands of the plant must be met from either the 
AA-CAES or molten salt systems. Both AA-CAES and molten salt systems are capable of supplying mildtemperature heat $\left(<300^{\circ} \mathrm{C}\right)$ because of the operating temperatures of their thermal storage, with several authors suggesting that concentrated solar power would be suitable for medium grade heating in mining operations(Beath, 2012; Eglinton et al., 2013).

The storage alternatives we consider were selected from the large number of alternatives available based on practical considerations such as technology maturity, large-scale deliverability (greater than $10 \mathrm{MW}_{\mathbf{e}}$ ) and technology depreciation time. However, the methodology that incorporates the alternative technologies presented below is generic and can be adapted to incorporate other technologies.

Given :

- historical information for the solar radiation at the mine's location,

- the thermal and electrical demands of the mine,

- the unit capital costs of all generation and storage options within the superstructure, and

- efficiencies of all mechanical units (pumps, turbines, compressors, motors, generators),

the problem is to develop a full system model which can:

- simulate a range of renewable input conditions,

- identify cost-optimal designs for each input conditions, and

- evaluate the performance and reliability of each design in the context of different input scenarios,

subject to constraints on generation, storage, and discharge capacity, while meeting the process demands.

The next section presents the full system model which addresses the requirements noted above and the following section describes how designs are generated and their performance evaluated.

\section{Energy system models}

The full system is described by models for the generation and storage technologies. These are dynamic models which will be discretised into an algebraic system suitable for solution with off-the-shelf optimization software. An energy system design is defined by the capacities of the generation and storage units available:The full energy system model may be found in AppendixA. Only equations for the cost objective and reliability evaluation will be presented here.

\subsection{Cost minimization for design generation}

The nonlinear programming (NLP) optimization problem for the generation of feasible designs may be stated as follows:

Given the solar input conditions for the location $\left[\dot{G}_{\tau}^{\text {tot }}, \dot{G}_{\tau}^{D N I}\right]$ and the unit costs of the generation, storage and delivery units $\left(U_{i}^{\text {gen }}, U_{j}^{s} U_{j}^{\text {out }}\right)$, determine the optimal capacities of the units within the energy system $\left(A_{i}^{g e n}, C_{j}^{s}\right.$, and $\left.C_{j}^{\text {out }}\right)$ required to minimize the capital cost of the system

$$
C C=\sum_{i=1}^{n_{g}} U_{i}^{\text {gen }} A_{i}^{\text {gen }}+\sum_{j=1}^{n_{s}}\left(U_{j}^{s} C_{j}^{s}+U_{j}^{\text {out }} C_{j}^{\text {out }}\right)
$$

subject to design and demand constraints (Equations A.1 - A.26), where $n_{g}$ and $n_{s}$ are the number of available generation and storage options respectively.

The costs for generation units are based on installed areas, a key change from the previous works where the generation systems were costed based on peak energy output (Amusat et al., 2015a,b). The incorporation 
of areas rather than peak outputs allows the designs to be compared based on nominal output and provide a more realistic approach to costing.

Solving of the cost minimization problem (Eq. 7) yields information not only on the sizes of units but also the distribution of energy at each time step, from generation to storage to demand satisfaction.

A feature of the optimization procedure is that the operating scheme is determined by the optimizer. For the first time step for example $(\tau=0)$, the optimizer makes decisions on how energy is to be released from the storage options (such as whether discharge should occur from one or multiple storage options to meet the electricity demands, and whether the same storage option should be used to satisfy heating and electrical demands). Such decisions are made at every time step. The optimizer therefore determines how the integrated system should be operated to best make use of the available renewable energy.

The optimization problem solved here is a single objective problem with full demand satisfaction incorporated as a design constraint (Eqs. A.25 and A.26).

\subsection{Evaluation of design reliability}

Next, each design generated is evaluated in terms of its reliability and demand satisfaction performance. The capabilities of the designs are investigated under a variety of solar input conditions. For each input solar profile, the external energy, $E E$ [MWh], required for each design to meet demand is minimized subject to constraints defined by the capacities of each unit determined by the initial design step. This requires that the same model (described in AppendixA) be solved again but with a different objective function and additional constraints. Mathematically:

$$
\min E E=\sum_{\tau}\left[\left(\dot{D}_{\tau}^{e l}+\sum_{s} \dot{E}_{s, \tau}^{h}\right)-\left(\dot{E}_{\tau}^{d}+\sum_{j=1}^{3} \dot{E}_{j, \tau}^{\text {out }}\right)\right] \cdot \Delta t
$$

subject to design constraints (Equations A.1-A.24) and capacity constraints:

$$
\begin{array}{cc}
A_{i} \leq A_{i}^{\text {gen,design }} & \forall i \\
C_{j}^{s} \leq C_{j}^{\text {s,design }} & \forall j \\
C_{j}^{\text {out }} \leq C_{j}^{\text {out }, \text { design }} & \forall j
\end{array}
$$

$A_{i}^{\text {gen,design }}, C_{j}^{s, d e s i g n}$ and $C_{j}^{\text {out,design }}$ refer to the capacities obtained from the first optimization problem. Equations (9)-(11) ensure that the capacities of the design being evaluated are not exceeded.

It is assumed that the thermal demands are prioritized: any deficit in energy will only affect the electricity supply. This assumption simplifies the model by eliminating one extra variable (thermal energy shortfall per time step) and an extra set of equations (representing the thermal demand balance) without affecting the solution of the optimization problem; the only change is the type of the shortfall incurred (thermal and/or electrical). Removal of this assumption will mean that an extra term accounting for the external thermal requirements will be required in Eq.(8).

A non-zero value for the external energy $(E E>0)$ indicates that the design would generate insufficient energy to satisfy the demands of the plant under the test solar radiation conditions, resulting in demand shortfall.

Each design is evaluated for a number of different solar input conditions $\left(N_{\text {eval }}\right)$. Based on the external energies obtained for each design during evaluation, the LPSP is evaluated as shown in Equation 4.

The average expected energy not supplied, EENS [MWh], for each design is also calculated based on the external energy results obtained for the individual scenarios. The expected energy values are weighted by the probability of the solar radiation evaluation profiles. Thus, equation 5 becomes :

$$
E E N S_{\text {design }}=\frac{\sum_{z=1}^{N_{\text {eval }}}\left[\left.p_{z} \cdot E E_{\text {design }}\right|_{z}\right]}{\sum_{z=1}^{N_{\text {eval }}} p_{z}}
$$


where $p_{z}$ is the probability of profile $z$ occurring. The denominator is a normalization factor for the probability term, required since not all possible solar profiles are evaluated in the model.

Each solar profile is made up of a number discrete values generated from probability distributions. Hence, the probability of each profile is the product of the probabilities of the discrete values,

$$
p_{z}=\prod_{\nu=1}^{k} p_{z, v}
$$

Based on the EENS, the daily EIR (\%) is calculated as

$$
E I R_{\text {design }}=100 \cdot\left[1-\frac{E E N S_{\text {design }}}{\sum_{\tau}\left(\dot{D}_{\tau}^{\text {el }}+\sum_{s} \dot{E}_{s, \tau}^{h}\right) \cdot \Delta t}\right]
$$

The EIR provides information on the extent of design failure within scenarios.

To generate feasible designs and investigate the effect of variability on those designs, the model above requires $\dot{G}_{\tau}^{\text {tot }}$ and $\dot{G}_{\tau}^{D N I}$. We need to be able to simulate solar input conditions which reflect the degree of variability at the location of the mine. This challenge is addressed in the next section.

\section{Generation of solar radiation profiles}

In order to investigate the effect of variability, we need to be able to generate multiple different solar profiles, each of which is likely given the historial data.

Historical hourly data for instantaneous global horizontal irradiance, $\dot{G}^{\text {tot }}\left[\mathrm{Wm}^{-2}\right]$, is available for most locations around the world. Statistical properties for each instant in time can be estimated from the historical data. Possible hourly instantaneous global horizontal irradiance values may be generated using any distribution generator which takes into account the statistical behaviour of the data. A MATLAB function, PEARSRND, which takes into account four statistical properties, the mean, variance, skewness and kurtosis of the historical data, is used in the generation of random instantaneous data, from which solar profiles are generated.

While the mean and standard deviation are measures of spread, the skewness and kurtosis are measures of the shape of the distribution. The PEARSRND function implements the Pearson family of distributions (Pearson, 1916) which is made up of seven distributions: types I to VII. They cover any specified mean, standard deviation, skewness and kurtosis. Together they form a 4-parameter family of distributions that covers the entire skewness-kurtosis region (Lahcene, 2013). The PEARSRND function determines the most appropriate continuous distribution type for any set of data and generates random data based on the statistical properties of the data set, ensuring that those properties are preserved in the simulated data. This ensures that the simulated data mirrors the historical data, with any bias in the historical also reflected in the simulated data.

Discrete data are generated from the probability distributions. For probability distributions generated from historical data with $k$ measurements at time intervals of $\Delta k$, the generated data may be written as

$$
\dot{G}^{t o t}\left(t_{\nu}\right)=\dot{G}_{\nu}^{t o t} \quad \nu=1,2 \ldots k ; t_{\nu}=\nu \cdot \Delta k
$$

Solar profiles, such as used in Eq. A.1, are typically continuous functions. The discrete data must therefore be converted into a continuous form in some way. This is achieved using a simple piecewise step function, giving the continuous function as

$$
\dot{G}^{\text {tot }}(t)=\dot{G}_{\nu}^{t o t} \quad t \epsilon\left[t_{k}, t_{k+1}\right] ; \forall \nu
$$

Other more complex methods, such as linear and spline interpolations, may also be used to generate the continuous function. 
Algorithm 1 Algorithm showing the methodology for evaluating the effect of variability in renewables input on the performance of possible designs of the integrated energy system

1. Determine the number of designs to be generated $\left(N_{\text {design }}\right)$ and the number of design evaluations $\left(N_{\text {eval }}\right)$ required.

2. Generate $N_{\text {design }}$ GHI profiles for generation of designs based on PEARSRND distribution function. Evaluate corresponding DNIs with Louche model.

3. For each randomly generated solar profile $\bar{s}_{y}=\left[G H I_{y}, D N I_{y}\right]$, obtain optimal design parameters $x$ which minimize the capital cost:

$$
\min _{x} C C\left(x, \bar{s}_{y}\right) \quad \forall y=1,2, \ldots N_{\text {design }}
$$

4. Generate $N_{\text {eval }}$ GHI profiles for design reliability evaluation. Evaluate corresponding DNIs.

5. For each design, minimize external energy requirements for each evaluation profile $\bar{s}_{z}=\left[G H I_{z}, D N I_{z}\right]$,

$$
\min E E\left(\bar{x}_{y}, \bar{s}_{z}\right) \quad \forall \quad \forall y=1,2, \ldots N_{\text {design }} ; z=1,2, \ldots N_{\text {eval }}
$$

6. Evaluate design performance measures $L P S P_{\bar{x}}$ and $E I R_{\bar{x}}$ for each design

Several correlations exist for the estimation of direct normal irradiance (DNI) from GHI data. Two major types of models are available for this purpose: parametric and decomposition models. Wong and Chow (2001) provide a review of some of the available correlations. Due to lack of pertinent data required for parametric models, a decomposition model was implemented in this work. Work by Batlles et al. (2000) suggests that the performances of parametric and decomposition models are similar, with a maximum $2 \%$ root mean square error (RMSE) difference observed in their DNI predictions for Spain. The Louche model, adjudged by Batlles et al. (2000) to be the most accurate decomposition model, was implemented in this work, as described in Amusat et al. (2015a). The Louche model relates the clearness index $k_{t}$ (ratio of GHI to extraterrestrial irradiance) to the beam transmittance $k_{b}$ (ratio of beam to extraterrestrial irradiance), from which the beam irradiation may be calculated. DNI is related to the beam irradiation through the solar zenith angle (Duffie and Beckman, 2013).

The development of solar forecasting techniques for storage dispatch and planning has been a subject of significant interest recently, with Inman et al. (2013) and Widen et al. (2015) reviewing the most promising forecasting techniques developed for solar renewable data generation. The techniques are based on trends (daily and seasonal) observed in historical data and have proven accurate for short-term forecasting, making them ideal for operation scheduling and dispatch planning. In a design phase problem however, the aim is to generate designs (or evaluate performance) for a wide variety of input conditions: the generated solar profiles need to exhibit different properties. Forecasting techniques are unable to provide this and, when combined with the complex nature of most forecasting methods, are unsuitable for use in this problem. The methodology implemented in this work however allows us to generate multiple solar profiles which are different from each other while still taking into account historical behaviour in the form of probability distributions.

In summary, in order to investigate the effect of variability on the integrated energy system described in Section 3, a set of possible renewable input conditions are generated using the PEARSRND function (Section 5). For each of those input conditions, a cost-optimal design is generated by minimizing the capital cost required for $100 \%$ demand satisfaction. The reliabilities of the designs generated are then evaluated based on the minimization the external energy requirements for each design over a large number of input conditions (Section 4.2). The procedure is summarized in Algorithm 1.

\section{Case studies}

The scale of variability in renewable input is different in different parts of the world. We aim to explore the impact of such differences. The aim is to obtain an insight into not just how variability affects the 
performance of designs, but also how the capital cost and performance are affected by the scale of variability. Two case studies representing locations with different degrees of solar availability and variability are presented in this work, highlighting the inherent flexibility of the modelling approach adopted.

\subsection{Chilean case study}

The first case study considers Collahuasi mine (Lat. 22.3 $\mathrm{S}$, Long. 68.9 $\mathrm{W}$ ). Located in the Atacama region of Chile, the mine is jointly owned by Anglo American PLC (44\%), Glencore Xstrata PLC (44\%) and Japan Collahuasi Resources B.V (12\%), and is one of the largest copper reserves in the world.

The optimal design for consecutive winter days (July) was investigated. Winter was selected since the season with the least solar availability is known to determine the optimal design of the energy system (Amusat et al., 2015b). Electricity consumption data for the mine was obtained from the Chilean electricity dispatch authorities (CDEC-SING, 2016), with the hourly demand varying between 164 and 178MWh and a daily demand of $4104.25 \mathrm{MWh}$. The thermal demands of the plant were assumed to be $10 \%$ of the electrical demands due to lack of data. With direct heating accounting for $13 \%$ of the mining industry's energy end-use (Pellegrino et al., 2004), the assumption was considered reasonable.

Historical solar radiation data for the site was obtained from the Department of Geophysics at the University of Chile (University of Chile, 2012). The records contain instantaneous global horizontal irradiance (GHI) data for the location over a period of 10 years (2003-2012) recorded at half-hourly intervals, giving 48 measurements per day. Thus, for each 30-minute interval, ten data points were available. The number of points available is thus insufficient to develop an adequate stochastic representation of the variability. This challenge was addressed by assuming that the solar radiation behaviour for a given hour of the day for each day of the week is similar. This means solar radiation measurements taken at the same time every day within a week can be taken to represent a single day. The method has the advantage of minimizing the effect of errors and outliers in measurements since the dataset is much larger. Based on this approach, the data for seven days (July 12-18) were considered, giving 70 days of data, each with 48 daily measurements.

\subsection{Canadian case study}

The second case study considers the fictional scenario of the Chilean mine being sited in Alberta, Canada (Lat. $51.0^{\circ} \mathrm{N}$, Long. $114.0^{\circ} \mathrm{W}$ ). The choice of Canada as an alternative site for the mine was influenced by its significant mining activities, large variability in renewables availability and the availability of historical solar radiation data. Testing the methodology at a location with renewables input conditions quantitatively and qualitatively different from Chile allows us to demonstrate the methodology more generally. Historical data recorded at half-hourly intervals for the location over a period of 8 years (2005-2012) was obtained from the United States national solar radiation database (NREL, 2015). Using a similar approach to the Chile case study, data for seven winter days (January 12-18) were considered, giving 56 days of data, each with 48 daily measurements. Time-zone corrections were required for the Chilean data.

Table 1 shows the GHI statistical data (mean, standard deviation, skewness and kurtosis of the GHI data) for the two locations considered. Compared to Chile, Canada is seen to be characterized by lower radiation and higher variability. The aim is to investigate the effect of these differences on the performances of the energy systems.

The NLP optimization problems (defined in Sections 4.1 and 4.2) were implemented in GAMS 24.2 (GAMS Development Corporation, 2013), while the solar radiation modelling, scenario generation and LPSP calculations were implemented in MATLAB 8.3 (MATLAB, 2014). Hourly time steps were considered for the discretization of the entire model. The NLP optimization problem for the design generation was solved using Baron 12.7.3 (Tawarmalani and Sahinidis, 2005), while the design evaluation problem was solved with SNOPT 7.2 (Gill et al., 2005). The number of generated designs $\left(N_{\text {design }}\right)$ and number of design evaluations $\left(N_{\text {eval }}\right)$ were set at 250 and 10,000 respectively. The parameters used in the model are presented in Tables 2. The cost data, converted to appropriate units, are presented in Table 3. 
Table 1: Statistical properties of solar radiation data for Antofagasta (Chile) and Alberta (Canada). The properties were calculated based on historical data available from University of Chile (2012) and NREL (2015).

\begin{tabular}{|c|cccc|cccc|}
\hline \multirow{3}{*}{ Hour } & \multicolumn{4}{|c|}{ Atacama, N. Chile } & \multicolumn{4}{c|}{ Alberta, Canada } \\
\cline { 2 - 9 } & $\begin{array}{c}\text { Mean } \\
\left(W \cdot m^{-2}\right)\end{array}$ & $\begin{array}{c}\text { S.D. } \\
\left(W \cdot m^{-2}\right)\end{array}$ & $\begin{array}{c}\text { Skew } \\
(-)\end{array}$ & $\begin{array}{c}\text { Kurt } \\
(-)\end{array}$ & $\begin{array}{c}\text { Mean } \\
\left(W \cdot m^{-2}\right)\end{array}$ & $\begin{array}{c}\text { S.D. } \\
\left(W \cdot m^{-2}\right)\end{array}$ & $\begin{array}{c}\text { Skew } \\
(-)\end{array}$ & $\begin{array}{c}\text { Kurt } \\
(-)\end{array}$ \\
\hline 7.5 & 48.97 & 3.33 & 0.87 & 3.68 & - & - & - & - \\
8 & 143.34 & 6.77 & 1.15 & 4.47 & - & - & - & - \\
8.5 & 260.54 & 9.20 & 0.53 & 2.35 & - & - & - & - \\
9 & 356.51 & 11.04 & 0.99 & 5.06 & 20.24 & 6.63 & -0.32 & 2.42 \\
9.5 & 455.97 & 11.15 & 0.30 & 3.03 & 61.04 & 19.66 & -0.48 & 2.17 \\
10 & 545.66 & 11.88 & 0.28 & 3.06 & 104.28 & 33.85 & -0.50 & 2.10 \\
10.5 & 620.63 & 18.46 & -0.82 & 7.48 & 143.78 & 46.88 & -0.50 & 2.09 \\
11 & 676.15 & 14.32 & 0.17 & 4.41 & 174.46 & 60.01 & -0.33 & 1.83 \\
11.5 & 724.53 & 9.10 & 0.12 & 3.31 & 207.26 & 65.12 & -0.49 & 2.19 \\
12 & 761.31 & 12.28 & 0.12 & 2.73 & 231.62 & 63.84 & -0.52 & 2.29 \\
12.5 & 772.27 & 13.57 & 0.02 & 3.62 & 245.02 & 74.22 & -0.83 & 2.76 \\
13 & 767.72 & 11.24 & -0.14 & 3.88 & 245.91 & 64.79 & -0.28 & 1.78 \\
13.5 & 739.63 & 14.07 & 0.44 & 3.56 & 248.43 & 59.91 & -0.72 & 2.51 \\
14 & 695.49 & 13.49 & 0.46 & 4.13 & 220.11 & 58.42 & -0.50 & 2.26 \\
14.5 & 646.33 & 8.37 & 0.63 & 2.37 & 189.40 & 52.99 & -0.34 & 1.92 \\
15 & 571.76 & 9.74 & -0.23 & 3.75 & 156.96 & 42.76 & -0.38 & 1.99 \\
15.5 & 489.76 & 9.05 & 0.18 & 4.17 & 114.57 & 31.42 & -0.35 & 1.99 \\
16 & 392.90 & 7.69 & -0.14 & 4.12 & 68.20 & 18.98 & -0.27 & 2.07 \\
16.5 & 285.57 & 9.40 & 0.74 & 5.46 & 23.82 & 7.66 & 0.20 & 2.26 \\
17 & 196.08 & 18.89 & 0.55 & 1.82 & - & - & - & - \\
17.5 & 77.98 & 2.23 & -0.70 & 2.79 & - & - & - & - \\
\hline
\end{tabular}

Table 2: Parameters used in case studies

\begin{tabular}{|lll|}
\hline Generation/Storage & Description & Source(s) \\
\hline PV system & Silicon solar panels, $\eta^{\text {inv }}=0.95$ & Paatero and Lund (2007) \\
Power Tower & $\alpha=0.9, \varepsilon=0.83, \eta^{\text {hel }}=0.668$, concentration ratio $=$ & Behar et al. (2013); \\
& 1000 & Fichtner (2010) \\
PHES & $h=700 m, \eta^{\text {pump }}=0.85, \eta^{\text {tur }}=0.90$ & Deane et al. (2010); \\
& Design compression and expansion ratio $=50$. & Barnes and Levine (2011) \\
AA-CAES & Concrete TES $\left(T_{m a x}^{T E S}=620^{\circ} \mathrm{C}\right)$. & Zunft et al. (2006); \\
& $\eta^{\text {comp }}=0.85, \eta^{\text {motor }}=0.90, \eta^{\text {gen }}=0.90$ & Hartmann et al. (2012); \\
& $60 / 40 ~ N a N O_{3} / \mathrm{KNO}_{3}$ salt mixture. Tank operating & Kim et al. $(2012)$ \\
Molten salt system & Ortega et al. (2008); \\
& temperatures of $290^{\circ} \mathrm{C}$ and $565^{\circ} \mathrm{C}$. Power block & Medrano et al. (2010); \\
& efficiency between 0.154 and 0.397 & Garcia et al. (2011) \\
\hline
\end{tabular}


Table 3: Unit costs for generation and storage options in superstructure

\begin{tabular}{|c|c|c|c|}
\hline Description & Cost & Source & Comment(s) \\
\hline Photovoltaic modules & $173.6 € / \mathrm{m}^{2}$ & Lazard (2014) & $\begin{array}{l}\text { Converted under nominal } \\
\text { conditions }\end{array}$ \\
\hline Power Tower & $410.2 € / \mathrm{m}^{2}$ & NREL (2012) & $\begin{array}{l}\text { Combination of heliostat field, } \\
\text { tower, receiver and indirect } \\
\text { costs. }\end{array}$ \\
\hline Energy storage in AA-CAES & $70 € / \mathrm{KWh}$ & Kloess (2012) & - \\
\hline Electricity generation from AA-CAES & $600 € / \mathrm{KW}_{\mathrm{e}}$ & Kloess (2012) & - \\
\hline Energy storage in PHES storage & $30 € / \mathrm{KWh}$ & Kloess (2012) & - \\
\hline Electricity generation from PHES & $500 \in / \mathrm{KW}_{\mathrm{e}}$ & Kloess (2012) & - \\
\hline Molten salt tank storage & $28 \in / \mathrm{KWh}$ & NREL (2012) & - \\
\hline Molten salt electricity generation & $884 \in / \mathrm{KW}_{\mathrm{e}}$ & NREL (2012) & - \\
\hline
\end{tabular}

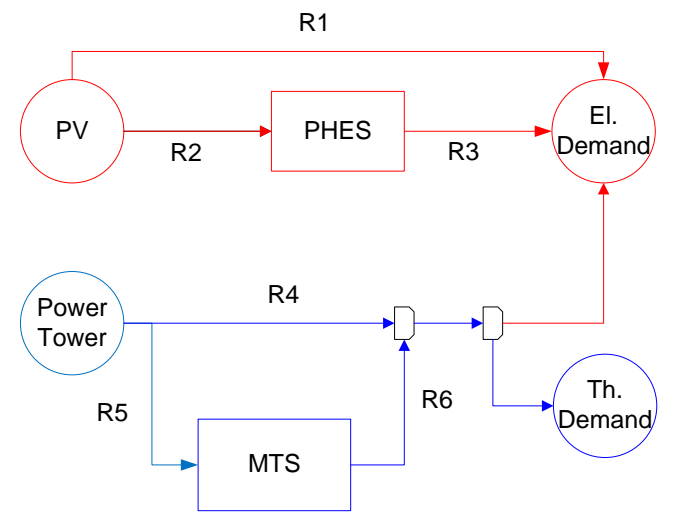

Figure 2: Optimal energy system configuration with possible energy routes for Chile. The red and blue lines represent the electrical and thermal networks respectively.

\section{Results and discussion}

\subsection{Chile}

\subsubsection{Optimal energy system description}

For the Chilean case study, the configuration of the energy system is unchanged by variability, with the same set of options selected irrespective of the energy input scenario (Figure 2). For all the scenarios generated, the optimal design involves the installation of both generation options to meet the demands. The PV system is integrated with pumped hydro storage (PHES), with the AA-CAES system eliminated from the superstructure. The molten salt storage system meets all the thermal demands and a significant portion $(>99 \%)$ of the electrical demands.

The installed capacities of the MTS steam generators were slightly less than the peak demand of 178 MW, varying between 175.5 and 176.4 MW, while the installed PHES turbine capacities vary from 1.5-2.0 MW. Figure 2 shows the possible energy routes within the system. The thermal system acts as the primary source of energy to the plant, with the power tower supplying during the day (R4) and the MTS system at night (R6). For most time periods, the electrical demand of the mine is below the installed generator capacity and demand is fully satisfied from the thermal system. Excess thermal energy is sent to the MTS (R5), while all the PV generation is stored in the PHES (R2).

However, in some time periods, the electrical demand of the plant exceeds the installed capacity of the MTS steam generator. At such times, the shortfall of energy is supplied from PV during the day (R1) and/or PHES (R3). The PHES system therefore acts as a secondary electricity source used in peak shaving and is only in operation in the hours with the highest electrical demands, taking advantage of its comparatively low generation cost (Table 3). 


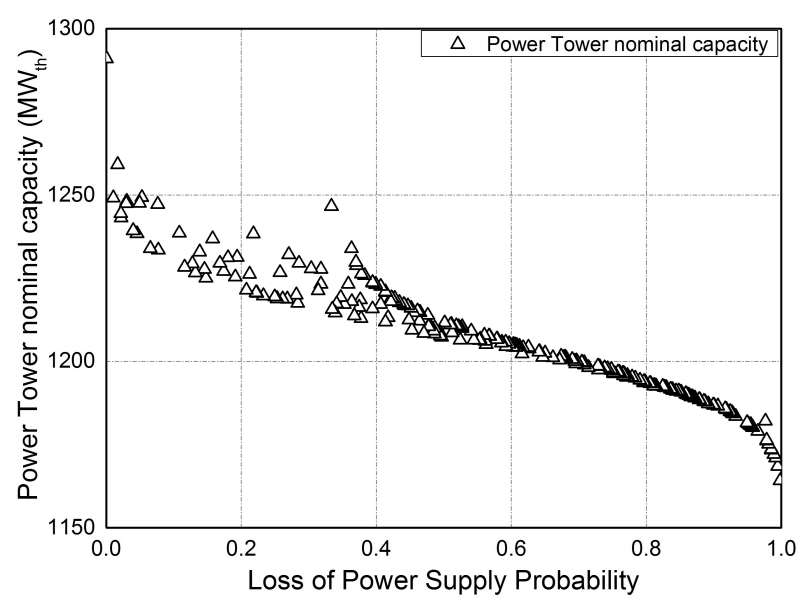

(a) Power Tower

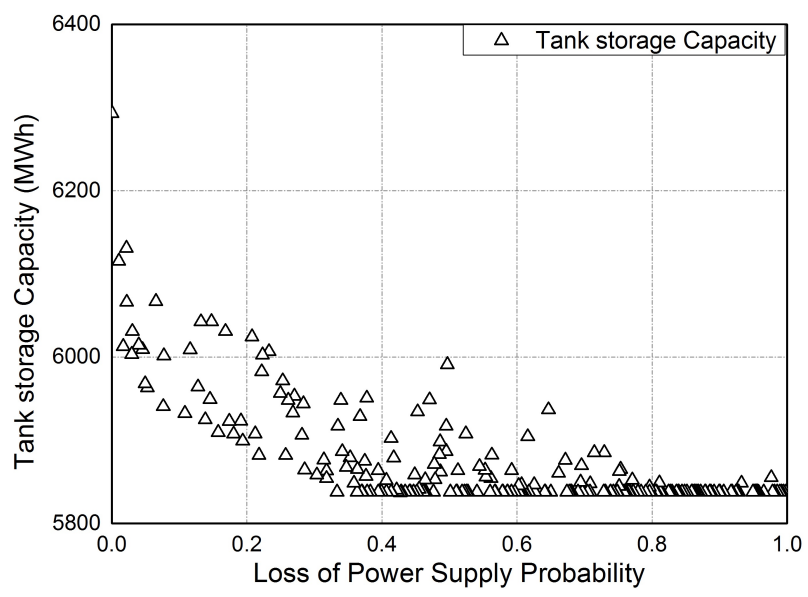

(c) Molten salt tank storage

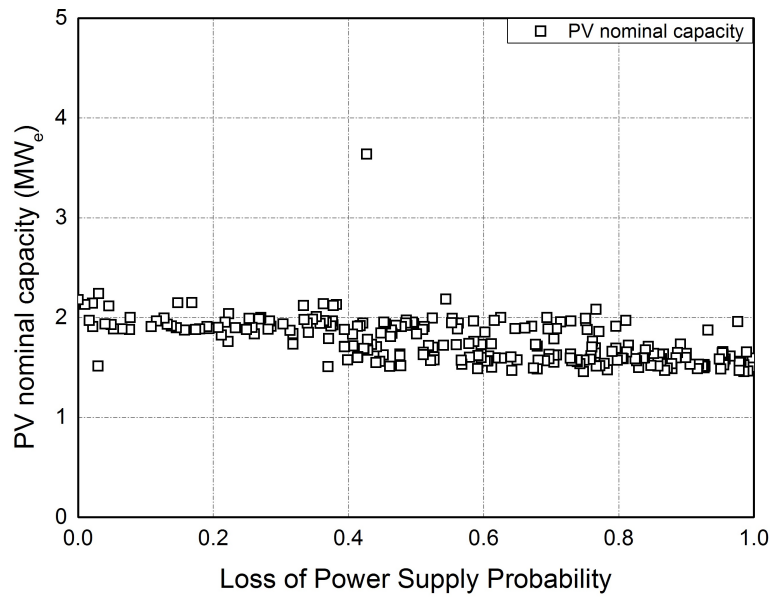

(b) PV

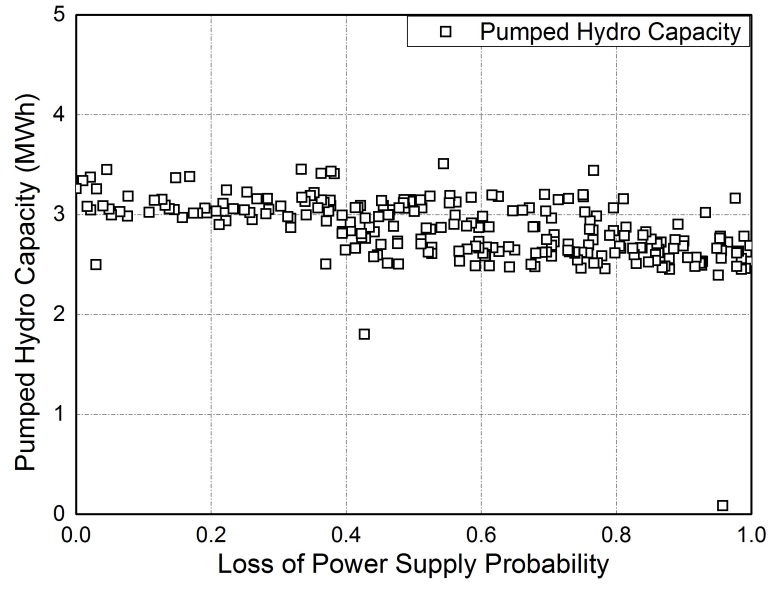

(d) Pumped hydro storage

Figure 3: Effect of renewables variability on installed capacities of generation and storage units for first case study

The choice of the power tower as the preferred generation option is due to the high ratio of the peak-tonominal capacity obtained with the system compared to that obtained with photovoltaics. Power towers are able to operate at over $95 \%$ of their nominal capacities even in winter. In contrast, the low GHI available in winter forces photovoltaics to operate at about $70 \%$ of the nominal capacity installed, meaning the cost of generation is almost doubled. This, combined with the higher solar-to-electrical efficiencies recorded with the power tower (about 22.9\%) when compared with photovoltaics (12.4\% peak based on Equation A.2) makes power towers the preferred choice for electricity generation, despite the lower unit cost of photovoltaics.

\subsubsection{Effect of variability on generation and storage systems}

The effect of variability on the installed capacities for generation and storage is shown in Figure 3. Each data point represents a design capacity obtained in the design generation phase. The abscisssa gives the likelihood of a given design (defined by two generation and storage capacities) being unable to satisfy the demands of the plant, thus providing a measure of reliability. Moving from left $(\mathrm{LPSP}=0)$ to right $(\mathrm{LPSP}=1)$ indicates decreasing reliability. A value of LPSP $=0$ means that the design was able to meet the daily demands for all the scenarios it was tested for, while a value of LPSP $=1$ means that the design was unable to fully satisfy the plant demands in any of the scenarios it was evaluated under.

The reliability of the energy system increases with increasing capacity, as expected. The difference between 


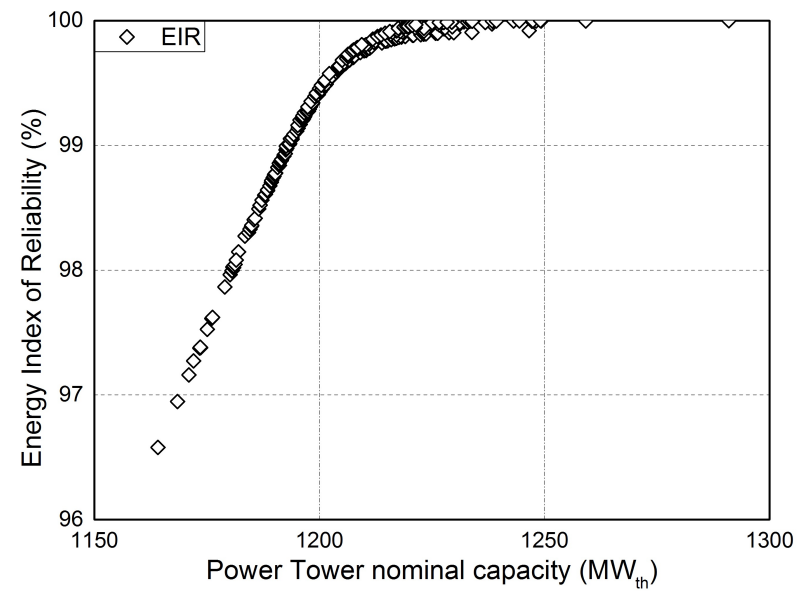

Figure 4: Plot of EIR against installed tower capacity

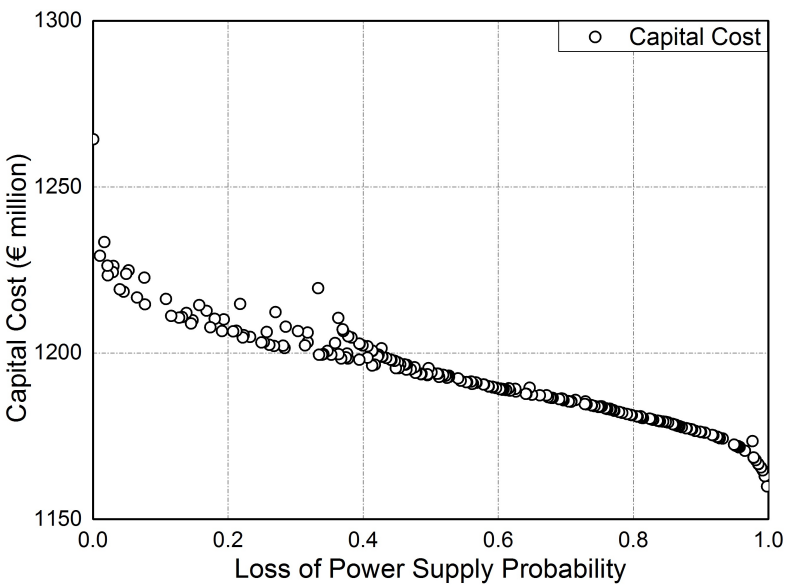

Figure 5: Effect of variability on capital cost

the largest and smallest installed capacities of the power towers is $127 \mathrm{MW}_{\text {th }}$, approximately $10 \%$. The small capacity difference observed over the entire reliability range reflects the low variability in the hourly solar radiation data (Table 1 ). The total daily direct normal radiation for the 10,250 profiles generated was within $6.25 \%$ of the mean value of $8855 \mathrm{Wh} \cdot \mathrm{m}^{-2}$.

The increase in power tower capacity with reliability is almost linear, particularly for systems with high LPSP (greater than 0.5). At higher reliabilities however, several designs with different generation capacities but roughly the same reliability occur. This is because for the lower cost systems, the reliability of the energy system is dictated primarily by the capacity of the generation system, with the storage capacity remaining at roughly the same level (Figure 3c). In the design evaluation phase, the LPSP of the system is most affected by the constraint on the generation capacity (Equation 9), with the other two capacity constraints remaining the same for the designs. Thus, an increase in the generation capacity translates to an increase in reliability. As the cost of the energy system increases however, the optimal solution becomes a trade-off between increasing the capacities of the generation and storage units, meaning the constraints on the storage units (Equations 10 and 11) play a more important role in determining the reliability of the system. The reliability of the system is therefore dependent on the direction of change of both the generation and storage capacities. This makes it possible for multiple designs to have different generation capacities but similar reliabilities as seen in the results.

The reliability of the energy system increases with storage capacity, with the capacity increasing by $8 \%$ over the entire reliability range. The results suggest that the minimum storage capacity required to operate the system for a 24-hour period is $5837 \mathrm{MWh}$.

The capacities of the installed PV and PHES systems are observed to remain at approximately the same level over the entire reliability range. This is expected, since these systems are only required for peak demand shaving.

Figure 4 shows, on the average, the percentage of the electrical demands which will be satisfied by the energy system for various installed capacities of the power tower. For smaller systems $\left(<1220 \mathrm{MW}_{\text {th }}\right)$, changes to the capacity have significant impacts on the fraction of the demand met. For larger systems however, increasing the generation capacity has little effect on the EIR even though the system reliability is improved. This indicates that a trade-off between capacity (a measure of cost) and EIR (a measure of performance) can be used in determining the optimal capacity of the system. The results also suggest that all the designs will, on the average, meet over $95 \%$ of the electrical demands and reflects the low variability in solar conditions for the location. However, the results do not imply that $95 \%$ of the demand will always be met. Based on the maximum of the expected energies obtained during the evaluation phase, the worst case design is guaranteed to meet at least $90.7 \%$ of the electrical demands of the plant. 


\subsubsection{Effect of variability on capital cost}

Figure 5 shows the effect of variability on the capital cost and reliability of the energy system. The capital cost expectedly increases with increasing reliability. The results indicate that increasing the reliability of the energy system from zero to $99 \%$ increases its capital cost by approximately $9 \%$. The cost of generation was observed to be the highest contributor to the capital cost, accounting for over $85 \%$. This is reflected in the cost profile which mirrors the capacity profile obtained for the power tower, the chief generation option.

The design with the lowest capital cost was generated by the best solar profile (highest total daily radiation) generated during the design phase, and is thus akin to the best case scenario. The design has the smallest possible nominal generation capacity (Figure 3a). Such a design has low reliability and will rarely meet the demands, meaning a secondary energy source (diesel generators for an off-grid plant) is often required. The drawbacks of the design are therefore the significant operating and transport costs, high $\mathrm{CO}_{2}$ emissions and the additional cost of investment in generators. A minimum-cost design is more likely to suit an already operational mine looking to expand or switch to renewables, since investment in new diesel generation capability will not be required.

The design with the highest capital cost was generated by the scenario with the least solar availability and may be considered the worst-case design obtained. The design has the highest generation and storage capacities of any of the designs (Figures 3a and 3c). Such a design will meet demands almost always, ensuring that auxiliary generation is seldom required. This design also has the lowest operating cost and minimum emissions.

The cost of increasing system reliability (decreasing LPSP) increases as the reliability increases. The difference in cost between the least reliable system and the system with LPSP $=0.1084$, representing a reliability increase approximately of $90 \%$, is $€ 56 \mathrm{~m}$. This represents a $5 \%$ increase in costs. A $10 \%$ increase in reliability from $90 \%$ to $99 \%$ (LPSP $=0.01$ ) would require an investment of $€ 13 \mathrm{~m}(1.1 \%$ increase). To increase the reliability even further to $99.9 \%$ (representing a further $0.9 \%$ increase) would cost $€ 35 \mathrm{~m}$, a cost increase of $2.9 \%$. The increase in reliability at that point may not be worth the extra cost incurred. In order to determine the optimal design point (beyond which the gain in reliability is not worth the cost), a full Pareto front is required.

The cost per unit output power of the most expensive design generated is $€ 7135 / \mathrm{kW}_{\mathrm{e}}$ ( $€ 1270$ million for 178 $\mathrm{MW}_{\mathrm{e}}$ ). Gemasolar power plant, a $20 \mathrm{MW}_{\mathrm{e}}$ plant sited in Seville, Spain and based on the same technology and 15 hours of storage cost $€ 230$ million, giving a cost per unit power of $€ 11500$ per $\mathrm{kW}_{\mathrm{e}}$ (National Renewable Energy Laboratory, NREL, 2016b). A technological assessment for the location of a power tower generation plant with 6 hours of storage and power thermal-to-electrical efficiency of 0.425 in Midwestern United States estimated the unit cost of power to be about $€ 6550 / \mathrm{kW}_{\mathrm{e}}$ (NREL, 2012). Other literature also predict similar costs (Hinkley et al., 2011). The cost values obtained in the study therefore agree with both theoretical estimates and actual plant costs.

As expected, the results from this case study reveal little spread in the capacity and cost results over the entire reliability range for a system with low variability. The results also indicate that all the designs perform well in terms of load satisfaction (EIR). For such systems, deterministic decision making (such as expected-value design) is unlikely to cause significant losses in cost and performance.

It is expected that a location with higher variability in renewables input will reveal a larger spread in the predicted designs and capital costs over the entire reliability range. This expectation is tested in the second case study.

\subsection{Canada}

\subsubsection{Optimal energy system description}

The optimal solution involves the installation of only the power tower for generation and the molten salts tank system for storage. The decision to completely eliminate PV generation from the optimal superstructure is due to the low GHI available at the location during winter (Table 1): any photovoltaic installation would only operate at about $25 \%$ of its nominal capacity.

Figure 6 summarizes the optimal system configuration and possible energy paths within the system. During the day when high solar radiation is available, the demands of the plant are satisfied by direct heat supply 


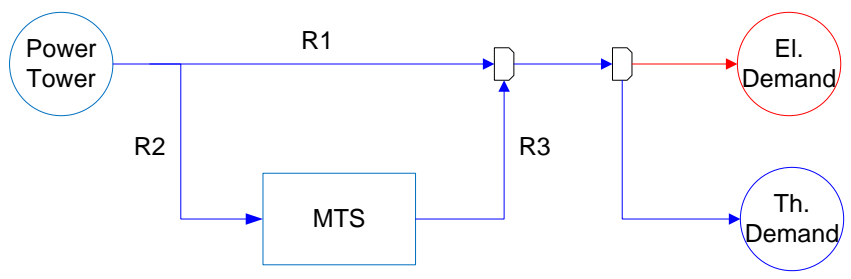

Figure 6: Optimal operating scheme for designs with possible energy routes for Canada case study. The red and blue lines represent the electrical and thermal networks respectively.

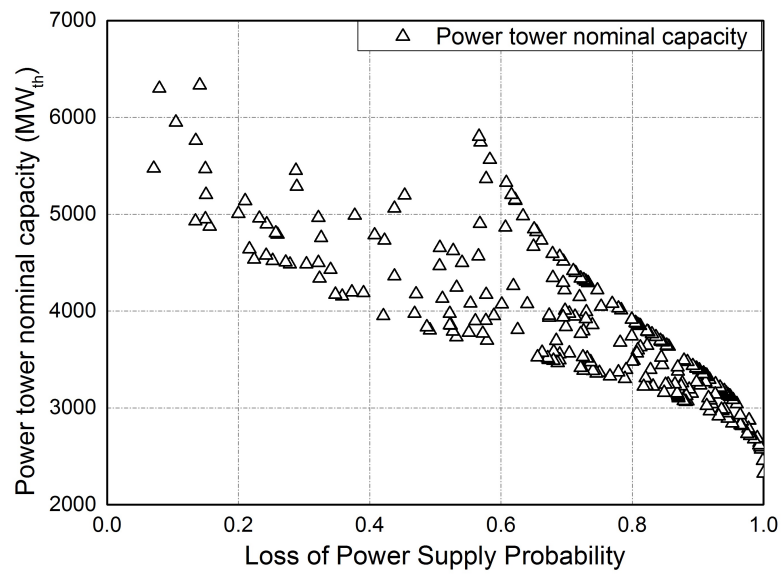

(a) Power Tower

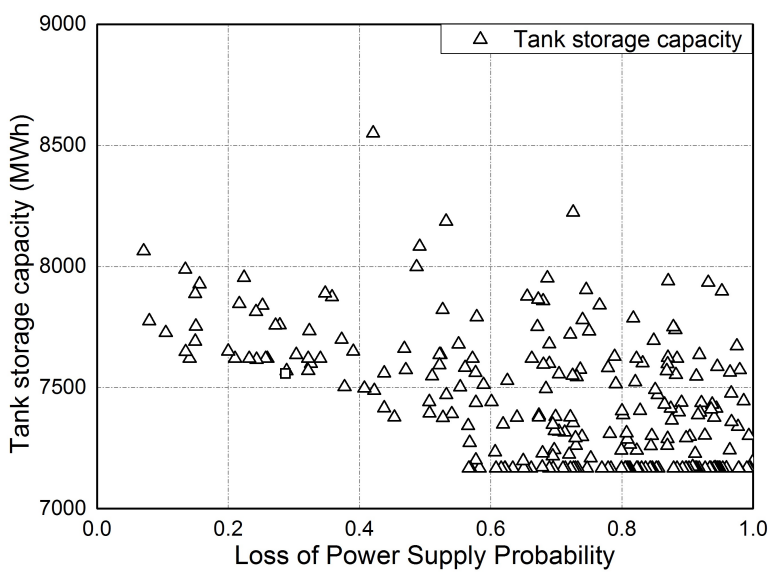

(b) Molten salt tank storage

Figure 7: Effect of renewables variability on installed capacities of generation and storage units for second case study

from the power tower (R1), with excess generation channelled to the MTS system (R2) until the store is full. When this occurs, only enough thermal energy to meet the demand of the mine is collected, with any excess heat dumped. Once sunlight is unavailable (during the night), the demands of the mine are satisfied solely from storage (R3). During periods of low insolation (early morning, early evening or sudden reduction in solar radiation availability), the demands are satisfied from a combination of direct supply and storage (R1 and R3).

\subsubsection{Effect of variability on generation and storage systems}

The effect of variability on the installed capacities for generation and storage is shown in Figure 7 . The capacities of the generation and storage units are larger than those required for the first case study due to the availability of lower amounts of solar radiation for shorter periods. The trends observed with this system are similar to those for the first study, with the capacities of the generation and storage units increasing with reliability. The increased variability in the input data increases the feasible region of possible generationstorage combinations, reflected by the larger scatter in the results.

For a given reliability, designs with larger generation capacities (generated by poor solar profiles) have slightly smaller storage capacities; see Figure 8 which shows the capacities of all designs with $L P S P=0.67$. While the designs with smaller generation capacities are constrained by the amount of energy that can be generated, the designs with larger generation capacities are limited by the amount of energy that can be stored. Thus, though the designs have the same reliability, they perform optimally under different conditions.

The difference in capacity between the smallest and largest generation units is $3976 \mathrm{MW}_{\text {th }}$, representing an increase of over $170 \%$. This is almost 15 times the capacity increase observed for the first case study. The large difference in capacity observed over the reliability range is due to high variability (Table 1), with the daily direct normal radiation for the profiles generated deviating from the mean of $3004 \mathrm{Wh} \cdot \mathrm{m}^{-2}$ by up to $70 \%$. The results also suggest that the minimum storage capacity required for daily operation is $7167 \mathrm{MWh}$. 


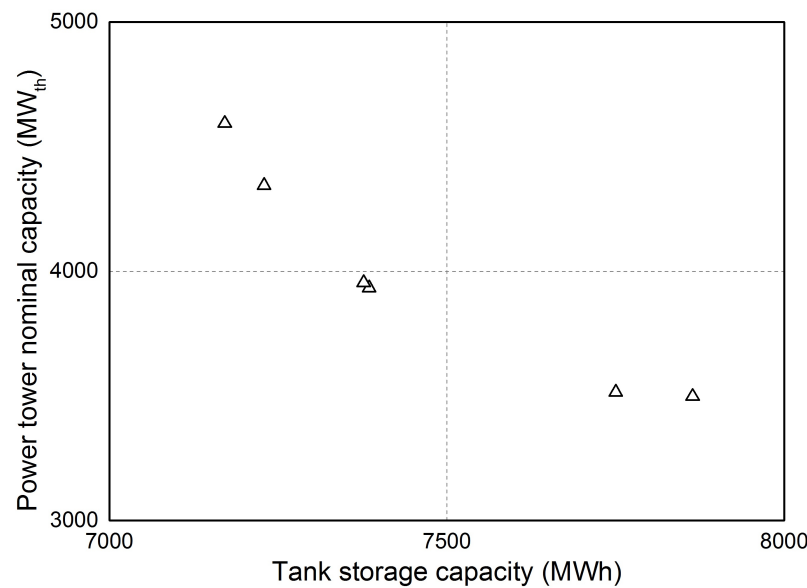

Figure 8: Plot of generation against storage capacities for designs with $\mathrm{LPSP}=0.67$

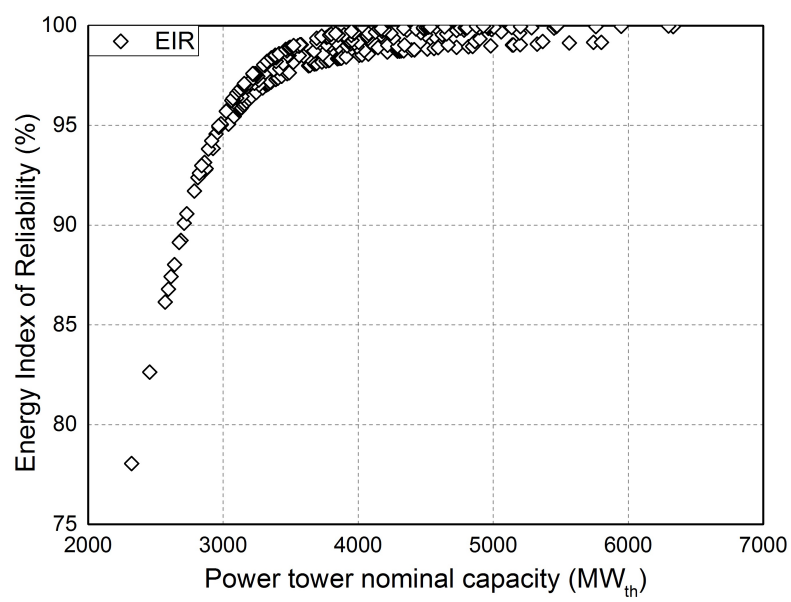

Figure 9: Plot of EIR against installed capacity for Alberta, Canada

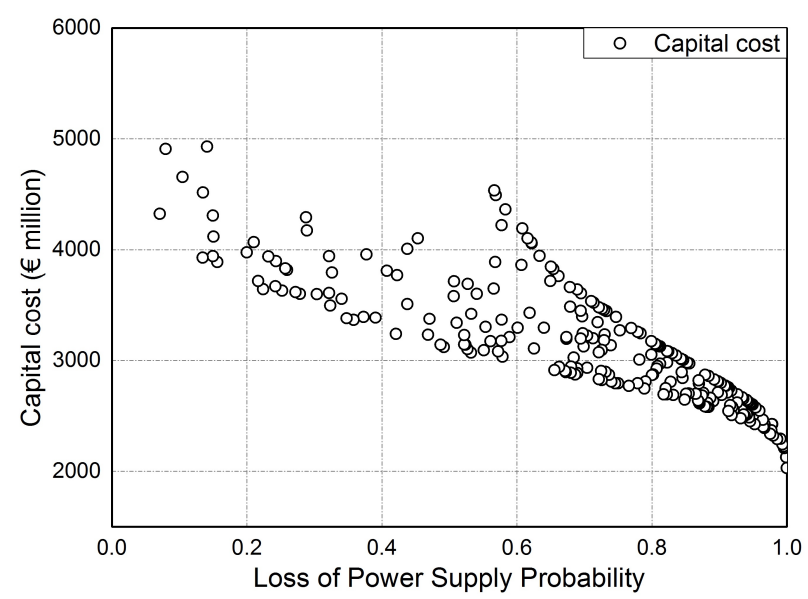

Figure 10: Effect of reliability on capital cost for Alberta,Canada

Figure 9 shows, on the average, the percentage of electrical demand that will be satisfied by the energy system for various installed capacities of the power tower. The trend of the system is similar the first case study (Figure 4). However, the fraction of the electrical demand unsatisfied is much higher for the Canada case because of the higher variability. In this case, a design for the worst case generated will, on the average, need $22 \%$ of the electrical demands to be met externally. Based on the maximum of the expected energies obtained during the evaluation phase, the worst case design is only guaranteed to meet about $20.6 \%$ of the electrical demands of the plant. This suggests that under unfavourable solar conditions, significant portions of the energy demands will be sourced externally. These results, when compared with the results for the first case study, indicate that designs with similar frequencies of failure (LPSP) perform worse in terms of extent of failure (EIR) as variability is increased.

\subsubsection{Effect of variability on capital cost}

Figure 10 shows the effect of variability on the capital cost and reliability of the energy system. The results indicate that increasing the reliability of the energy system from zero to $95 \%$ doubles the cost of the system. The larger cost difference over the reliability range is due to the high variability in solar energy input when compared to Chile. 
Table 4: Direct normal irradiation measurements for locations in Chile and Canada.

\begin{tabular}{ccc}
\hline Location & Avg. daily DNI, $\mathrm{kWh} / \mathrm{m}^{2} /$ day & Avg. annual DNI, $\mathrm{kWh} / \mathrm{m}^{2}$ \\
\hline San Pedro de Atacama , N.E. Chile & 9.16 & 3343 \\
Swan hills, Alberta & 3.46 & 1263 \\
\hline Source: NASA Langley Atmospheric Sciences Data Center (2008)
\end{tabular}

The cost profile highlights a key disadvantage of purely deterministic decision making (such as expectedvalue designs) for systems with high variability. The presence of multiple designs with the same reliability suggests that such designs will not only be sub-optimal in terms of reliability and cost, but also run the risk of missing the trade-off curve completely. The potential losses in terms of cost and performance, when a design decision is made using data that ignore the stochasticity in the real behaviour of renewables, are also much larger for an energy system located in a region with high variability in renewables input.

The high costs obtained for the designs in the Canadian study reflects the poor solar availability at the location. Table 4 compares the annual measurements of DNI for the regions considered in the case studies. Only a third of the solar radiation available in Chile is available in Canada, and this is reflected in the capital costs of the designs. However, while solar thermal technologies are mostly installed in regions with intense solar radiation, some countries with relatively poor solar radiation (less than $2000 \mathrm{kWh} / \mathrm{m}^{2}$ per year) are currently considering solar thermal generation as a way to reduce greenhouse emissions in power generation, with some already investing the technology. For example, the possibility of using solar thermal generation to supplement power generation and reduce greenhouse emissions in Canada is already being considered with a $1 \mathrm{MW}_{\mathrm{e}}$ integrated solar combined cycle plant under demonstration in Alberta (MacKenzie et al., 2014; National Renewable Energy Laboratory, NREL, 2016a). The plant integrates solar thermal generation (parabolic trough technology with no storage) with combined cycle generation. The total cost of the project was $\$ 9$ million, with a third of the funding provided by the city council of Medicine Hat, Alberta. Other countries with similar levels of solar radiation currently demonstrating solar thermal technology include Germany and Thailand (National Renewable Energy Laboratory, NREL, 2016c). While the costs appear high, they are comparable to the cost of diesel generation over the lifetime of the mine as is shown in AppendixB.

While the cost profile presented here is possibly a crude approximation to the curve representing the trade-off between cost and demand satisfaction, it does give an insight into what to expect when a multi-objective optimization technique designed to identify the full pareto curve is applied to the cost-reliability problem. For a given reliability, the capital cost of the energy system increases with generation capacity (right to left in Figure 8, for example). Thus, from a cost perspective, the best design at a given reliability is the design with the smallest generation capacity at that reliability. The vector of such designs over the entire reliability range forms the set of non-dominated solutions (designs for which one objective cannot be improved without worsening the other) for the trade-off curve, from which a decision on the design to be selected may be made based on other factors such as operating costs or $\mathrm{CO}_{2}$ emissions.

The results of the two case studies show that the degree of variability in renewables availability can have a significant effect on energy system design and performance. Designs based on fixed renewable input conditions (as is common in literature), while optimal for the scenario for which they are generated, may be sub-optimal when the entire range of possible input conditions is considered. For example, an optimal design for $100 \%$ demand satisfaction generated based on mean solar input conditions will satisfy demand in only about $50 \%$ of possible input scenarios, with the degree and extent of failure in other possible scenarios dependent on the degree of variability at the location (how different the mean profile is from the worst case condition). As such, while the conventional approach to energy systems design in which fixed input conditions are considered may be sufficient for locations with low variability, it is wholly inadequate for locations with high variability as the effect on the cost and performance can be very significant, as was demonstrated with the Canada case study. Such a design approach also ignores the possibility of cheaper designs with similar performance levels (again demonstrated in the Canada case study). The stochastic nature of renewables input therefore needs be accounted for in some form at the design stage. The approach presented in this work can be used to evaluate how much effect renewables variability is likely to have on an energy system at any particular location, providing the decision-maker with important information at the 


\section{${ }_{543}$ Acknowledgements}

\section{Conclusion} research.

design stage. It also provides information about designs with similar cost and/or performance indices, thus providing the decision-maker with possible alternatives. The approach therefore provides the decision-maker with a different sort of information not which is not available with the conventional methods.

The effect of variability in the availability of renewable energy on the design and reliability of integrated energy systems has been investigated. A non-linear dynamic model for an energy system incorporating both thermal and electrical generation as well as large-scale storage has been developed. The variable nature of the renewables input is modelled using probability distributions generated from the statistical properties of historical data. The effect of variability on the design process has been investigated by carrying out a stochastic evaluation of the performance of deterministically-generated "cost-optimal" designs under possible solar input conditions generated from the probability distributions. Measures of reliability which consider the frequency and extent of demand satisfaction have been considered. Two case studies for locations with different degrees of renewables variability have been presented to demonstrate the capabilities of the model. The results show that range of system capacities and capital cost increase with increased variability, with demand satisfaction worsening.

Multi-objective optimization with stochastic modelling may be necessary to correctly identify the trade-offs between cost and reliability. In order for the methodology presented in this work to be applicable for this purpose, all feasible system designs would need to be generated and the active set of generation-minimizing designs determined. The large space of feasible renewable input conditions makes this a challenging task since there is a continuum of designs. The results obtained from this work however provide a good starting point for multi-objective stochastic optimization of the cost and reliability which will be the focus of future

The methodology presented has been shown to be suitable for a wide range of integrated energy design problems with variability in energy availability. It can be used as a first-attempt evaluation of any site and generation/storage combination. The evaluation of designs in terms of reliability and performance enables the decision maker to understand the trade-offs that may exist between cost and reliability, allowing the decision maker to choose the most appropriate design for the particular location of the mine.

The authors would like to acknowledge the funding provided by the Nigerian government through the presidential scholarship for innovation and development (PRESSID) scheme for this research. P.R. Shearing acknowledges funding from the Royal Academy of Engineering. 


\section{Nomenclature}

$\alpha \quad$ Receiver absorptivity, unitless

$\chi_{s}(t) \quad$ Salt fill level for tank s at instant $t$, unitless

$\Delta T^{c} \quad$ Temperature difference between compressor inlet and outlet [K]

$\Delta T^{\text {turbine }}$ Temperature difference between turbine inlet and outlet $[\mathrm{K}]$

$\Delta T_{s} \quad$ Difference between tank and ambient temperatures $[\mathrm{K}]$

$\Delta t \quad$ Time interval of charging or discharging $[h]$

$\eta^{c o m p} \quad$ AA-CAES compressor efficiency, unitless

$\eta^{g e n}$

$\eta^{\text {motor }}$

$\eta^{\text {pump }}$

$\eta^{s t}$

$\eta^{\text {turbine }}$

$\eta^{\text {tur }}$

$\eta_{\text {hel }}$

$\eta_{\text {inv }}$

$\eta_{p v}(t)$

$\gamma$

$\dot{D}^{e l}(t)$

$\dot{D}^{t h}(t)$

$\dot{D}_{\tau}^{e l}$

$\dot{E}^{d}(t)$

$\dot{E}_{s}^{h}(t)$

$\dot{E}_{\tau}^{d}$

$\dot{E}_{j, \tau}^{\text {out }}$

$\dot{E}_{j}^{i n}(t)$

$\dot{E}_{j}^{\text {out }}(t)$

$\dot{E}_{j}^{\text {out }}(t)$

$\dot{E}_{P V}^{g e n}(t)$

$\dot{E}_{s, \tau}^{h}$
AA-CAES generator efficiency, unitless

AA-CAES motor efficiency, unitless

PHES pump efficiency, unitless

Thermal-to-electrical energy conversion efficiency, unitless

AA-CAES turbine efficiency, unitless

PHES turbine efficiency, unitless

Heliostat efficiency, unitless

Inverter efficiency, unitless

Photovoltaic efficiency over generation period, unitless

Specific heat ratio, unitless

Instantaneous electrical demand [MW]

Instantaneous thermal demand [MW]

Electrical demands of plant during interval $\tau[\mathrm{MW}]$

Energy supplied directly from PV generation [MW]. Includes electrical energy to be dumped due to excess generation.

Instantaneous rate of heat addition to tank $s$ via heater [MW]

Direct electricity rate to plant from PV during interval $\tau$ [MW]

Electrical output from unit $j$ to plant over durng interval $\tau$ [MW]

Energy input into storage option $j$ [MW]

Energy supply rate to plant from storage option $j$ [MW]

Instantaneous electrical output from storage unit $j[\mathrm{MW}]$

Electrical energy output from PV [MW] terval $\tau[\mathrm{MW}]$
Heating requirement of tank $s$ during in-
$\dot{G}^{D N I}(t)$ Instantaneous direct normal irradiance $\left[W / m^{2}\right]$

$\dot{G}^{t o t}(t) \quad$ Instantaneous global horizontal irradiance $\left[W / m^{2}\right]$

$\dot{H}_{s}^{i n}(t) \quad$ Rate of enthalpy addition to storage tank $s$ during charge $[\mathrm{MW}]$

$\dot{H}_{s}^{\text {out }}(t) \quad$ Rate of enthalpy removal from storage tank $s$ during discharge [MW]

$\dot{m}_{P H E S}^{i n}(t)$ Mass flowrate of water into upper reservoir over charging period $[\mathrm{m} / \mathrm{s}]$

$\dot{m}_{P H E S}^{\text {out }}(t)$ Average flowrate of water out of upper reservoir during discharge $[\mathrm{m} / \mathrm{s}]$

$\dot{m}_{c}(t) \quad$ Average mass flowrate of air into compression system during charging $[\mathrm{kg} / \mathrm{s}]$

$\dot{m}_{t}(t) \quad$ Average mass flowrate of air into AACAES turbines during discharge $[\mathrm{kg} / \mathrm{s}$ ]

$\dot{Q}^{\text {conv }}(t)$ Rate of heat loss from absorber via convection [MW]

$\dot{Q}_{j}^{\text {heating }}(t)$ Heat to plant from storage option $j$ [MWh]

$\dot{Q}_{s}^{\text {loss }}(t) \quad$ Rate of heat loss from storage tank $s$ [MW]

$\dot{Q}^{r a d}(t)$

Rate of heat loss from absorber via radiation [MW]

$\dot{Q}^{T E S, i n}(t)$ Heat flowrate into TES [MW]

$\dot{Q}^{\text {TES,loss }}(t)$ Rate of heat loss from TES [MW]

$\dot{Q}^{\text {TES,out }}(t)$ Heat flowrate out of TES [MW]

$\dot{Q}_{P T}^{g e n}(t) \quad$ Thermal energy output from PT [MW]

$\rho \quad$ Density $\left[\mathrm{kg} / \mathrm{m}^{3}\right]$

$A_{c} \quad$ Total heliostat aperture area $\left[\mathrm{m}^{2}\right]$

$A_{i}^{g e n} \quad$ Area of generation unit $i\left[\mathrm{~m}^{2}\right]$

$A_{p} \quad$ Installed area of photovoltaics $\left[\mathrm{m}^{2}\right]$

$A_{\text {tank }} \quad$ Area of storage tank $\left[\mathrm{m}^{2}\right]$

$c_{p} \quad$ Specific heat capacity $[\mathrm{J} / \mathrm{kg} \cdot K]$

$C_{i}^{g e n} \quad$ Nominal capacity of generation option $i$ [MW]

$C_{j}^{\text {out }} \quad$ Energy supply capacity of storage option j [MWh]

$C_{j}^{s} \quad$ Storage capacity of option $j$ [MWh]

EE External energy requirement [MWh]

$E E N S_{y} \quad$ Probability-weighted expected energy not supplied for design $y$ [MWh]

$E I R_{y} \quad$ Energy index of reliability of design $y[$ Acceleration due to gravity $\left[9.81 \mathrm{~m} / \mathrm{s}^{2}\right]$

Reservoir height difference $[\mathrm{m}]$ 


$\begin{array}{lll}H_{s}^{\text {acc }}(t) & \begin{array}{l}\text { Instantaneous energy accumulation in } \\ \text { storage tank } s \text { [MWh] }\end{array} & R_{A} \\ i & \text { Generation option } & S_{j}(t) \\ j & \text { Storage option } & T^{T E S}(t) \\ L P S P_{y} & \begin{array}{l}\text { Loss of power supply probability for de- } \\ \text { sign } y, \text { unitless }\end{array} & T_{\text {cell }}(t) \\ m_{A A-C A E S}^{s} & (t) \text { Mass of air in cavern at instant t }\left[m^{3}\right] & \\ n & \text { Polytropic exponent for compression or } & U_{j}^{s} \\ & \text { expansion, unitless } & \\ N_{c} & \text { Number of compression stages, unitless } & U_{i}^{\text {gen }} \\ n_{g} & \text { Number of generation options } & U_{s}^{\text {loss }} \\ n_{s} & \text { Number of storage options } & U_{i}^{\text {out }} \\ N_{t} & \text { Number of AA-CAES expansion stages, } & \\ & \text { unitless } & V_{s} \\ N_{\text {design }} & \text { Number of designs } & y \\ N_{\text {eval }} & \text { Number of design evaluations } & z \\ p & \text { Exponent for salt fill level in heat loss ex- } & z \\ & \text { pression, unitless } & \end{array}$

Specific gas constant of air [286.7 J/kg.K] Accumulated energy in storage option $j$ at time $t$ [MWh except otherwise stated]

Temperature of thermal energy store $[\mathrm{K}]$ at time $t[\mathrm{~K}]$

Photovoltaic module cell temperature $\left[{ }^{\circ} \mathrm{C}\right]$

Energy-specific cost of storage option $j$ $[€ / \mathrm{kWh}]$

Unit cost of generation option $i\left[€ / \mathrm{m}^{2}\right]$

Tank heat loss coefficient $\left[\mathrm{W} / \mathrm{m}^{2} \cdot K\right]$

Capacity-specific cost of storage option $j$ $\left[€ / \mathrm{kW}_{\mathrm{e}}\right]$

Volume of thermal energy store $\left[\mathrm{m}^{3}\right]$

Design number, $y=1,2 \ldots N_{\text {design }}$

Design evaluation number, $z=$ $1,2 \ldots N_{\text {eval }}$ 


\section{References}

Abbes, D., Martinez, A., Champenois, G., Apr 2014. Life cycle cost, embodied energy and loss of power supply probability for the optimal design of hybrid power systems. Mathematics and Computers in Simulation $98,46-62$.

URL http://dx.doi.org/10.1016/j.matcom.2013.05.004

Al-Shamma'a, A., Addoweesh, K., 2014. Techno-economic optimization of hybrid power system using genetic algorithm. International Journal of Energy Research 38 (12), 1608-1623.

Amusat, O. O., Shearing, P. R., Fraga, E. S., July 2015a. Optimal integrated energy systems design incorporating variable renewable energy sources. In: Proceedings of the 3rd PRO-TEM Network Conference: Sustainable Thermal Energy Management in the Process Industries (SusTEM2015). Newcastle upon Tyne, pp. $245-253$.

Amusat, O. O., Shearing, P. R., Fraga, E. S., 2015b. System design of renewable energy generation and storage alternatives for large scale continuous processes. In: Gernaey, K. V., Huusom, J. K., Gani, R. (Eds.), Computer Aided Chemical Engineering. Vol. 37. Elsevier, pp. 2279-2284.

Baker, K., Hug, G., Li, X., Jul 2012. Optimal integration of intermittent energy sources using distributed multi-step optimization. 2012 IEEE Power and Energy Society General Meeting.

Barnes, F., Levine, J., 2011. Large Energy Storage Systems Handbook. Mechanical and Aerospace Engineering Series. Taylor \& Francis.

Batlles, F., Rubio, M., Tovar, J., Olmo, F., Alados-Arboledas, L., 2000. Empirical modeling of hourly direct irradiance by means of hourly global irradiance. Energy 25 (7), $675-688$.

Beath, A. C., 2012. Industrial energy usage in australia and the potential for implementation of solar thermal heat and power. Energy 43 (1), 261 - 272, 2nd International Meeting on Cleaner Combustion (CM0901Detailed Chemical Models for Cleaner Combustion).

URL http://www.sciencedirect.com/science/article/pii/S0360544212003118

Behar, O., Khellaf, A., Mohammedi, K., 2013. A review of studies on central receiver solar thermal power plants. Renewable and Sustainable Energy Reviews 23 (0), 12 - 39.

Blonbou, R., Monjoly, S., Bernar, J.-L., Jan 2013. Dynamic energy storage management for dependable renewable electricity generation. Energy Storage - Technologies and Applications, 271-294.

Bradshaw, R. W., Dawson, D. B., De la Rosa, W., Gilert, R., Goods, S. H., Hale, M. J., Jacobs, P., Jones, S. A., Kolb, G. J., Pacheco, J. E., et al., Jan 2002. Final Test and Evaluation Results from the Solar Two Project.

Castronuovo, E. D., Usaola, J., Bessa, R., Matos, M., Costa, I., Bremermann, L., Lugaro, J., Kariniotakis, G., Mar 2013. An integrated approach for optimal coordination of wind power and hydro pumping storage. Wind Energy 17 (6), 829-852.

Centro de Despacho Economico de Carga del Sistema Interconectado del Norte Grande de Chile (CDECSING), 2016. Retiros de energía a clientes. [Online]. Available in Spanish at: http://cdec2.cdec-sing . cl/, Accessed 04 May 2015.

Chauhan, A., Saini, R., Oct 2014. A review on integrated renewable energy system based power generation for stand-alone applications: Configurations, storage options, sizing methodologies and control. Renewable and Sustainable Energy Reviews 38, 99-120.

URL http://dx.doi.org/10.1016/j.rser.2014.05.079

Deane, J., Gallachoir, B., McKeogh, E., May 2010. Techno-economic review of existing and new pumped hydro energy storage plant. Renewable and Sustainable Energy Reviews 14 (4), 1293-1302. 
Departamento de Geofísica de la Universidad de Chile, 2012. Evaluación del recurso solar. [Online]. Available in Spanish at: http://walker.dgf.uchile.cl/Explorador/Solar2/, Accessed 31 March 2014.

Diaf, S., Belhamel, M., Haddadi, M., Louche, A., Feb. 2008. Technical and economic assessment of hybrid photovoltaic/wind system with battery storage in corsica island. Energy Policy 36 (2), 743-754.

URL http://www.sciencedirect.com/science/article/pii/S0301421507004788

Duffie, J., Beckman, W., 2013. Solar Engineering of Thermal Processes: Fourth Edition. John Wiley \& Sons, Inc., Solar Energy Laboratory, University of Wisconsin-Madison, United States.

Dufo-Lopez, R., Bernal-Agustin, J. L., Dec. 2008. Multi-objective design of pv-wind-diesel-hydrogen-battery systems. Renewable Energy 33 (12), 2559-2572.

URL http://www.sciencedirect.com/science/article/pii/S0960148108000724

Eglinton, T., Hinkley, J., Beath, A., Dell'Amico, M., 2013. Potential applications of concentrated solar thermal technologies in the australian minerals processing and extractive metallurgical industry. JOM 65 (12), 1710-1720.

ElDesouky, A. A., Nov. 2014. Security constrained generation scheduling for grids incorporating wind, photovoltaic and thermal power. Electric Power Systems Research 116 (0), 284-292.

Evans, D., Jan 1981. Simplified method for predicting photovoltaic array output. Solar Energy 27 (6), 555560.

Fichtner, 2010. Technology assessment of CSP technologies for a site specific project in South Africa final report. Tech. rep., The World Bank and ESMAP, Washington D.C.

GAMS Development Corporation, 2013. General Algebraic Modeling System (GAMS) Release 24.2.1.

Garcia, I. L., Ãlvarez, J. L., Blanco, D., 2011. Performance model for parabolic trough solar thermal power plants with thermal storage: Comparison to operating plant data. Solar Energy 85 (10), $2443-2460$.

Gill, P. E., Murray, W., Saunders, M. A., Jan 2005. SNOPT: An SQP Algorithm for Large-Scale Constrained Optimization. SIAM Review 47 (1), 99-131.

Gooding, P., Makram, E., Hadidi, R., Feb 2014. Probability analysis of distributed generation for island scenarios utilizing carolinas data. Electric Power Systems Research 107, 125-132.

Grazzini, G., Milazzo, A., 2012. A thermodynamic analysis of multistage adiabatic caes. Proceedings of the IEEE 100(2) (2), 461-472.

Hartmann, N., Vahringer, O., Kruck, C., Eltrop, L., 2012. Simulation and analysis of different adiabatic compressed air energy storage plant configurations. Applied Energy 93, 541-548.

Hinkley, J., Curtin, B., Hayward, J., Wonhas, A., Boyd, R., Grima, C., Tadros, A., Hall, R., Naicker, K., Mikhail, A., 2011. Concentrating solar power-drivers and opportunities for cost-competitive electricity. Clayton South: CSIRO.

Inman, R. H., Pedro, H. T., Coimbra, C. F., Dec 2013. Solar forecasting methods for renewable energy integration. Progress in Energy and Combustion Science 39 (6), 535-576.

International Energy Agency, Mar 2014. Technology roadmap: Energy storage. Tech. rep., International Energy Agency, [Online]. Available at: http://www.iea.org/publications/freepublications/ publication/TechnologyRoadmapEnergystorage.pdf (Accessed 11 April 2014).

Kaabeche, A., Ibtiouen, R., May 2014. Techno-economic optimization of hybrid photovoltaic/wind/diesel/battery generation in a stand-alone power system. Solar Energy 103, 171-182.

URL http://www.sciencedirect.com/science/article/pii/S0038092X14000954

Kim, Y.-M., Lee, J.-H., Kim, S.-J., Favrat, D., 2012. Potential and evolution of compressed air energy storage: Energy and exergy analyses. Entropy 14 (8), 1501-1521. 
Kloess, M., May 2012. Electric storage technologies for the future power system - an economic assessment. 9th International Conference on the European Energy Market.

Kueh, K. C., Nathan, G. J., Saw, W. L., Aug 2015. Storage capacities required for a solar thermal plant to avoid unscheduled reductions in output. Solar Energy 118, 209-221.

Lahcene, B., 2013. On pearson families of distributions and its applications. African Journal of Mathematics and Computer Science Research 6(5), 108-117.

Lazard, September 2014. Lazard's levelized cost of energy analysis - version 8.0. [Online]. Available at: http: //www . lazard.com/PDF/LevelizedCostofEnergy-Version8.0.pdf.

Ma, T., Yang, H., Lu, L., Mar 2014. Feasibility study and economic analysis of pumped hydro storage and battery storage for a renewable energy powered island. Energy Conversion and Management 79, 387-397.

MacKenzie, K., Bowers, R., Wacker, D., Drever, R., Jyoti, A., Kearney, D., 2014. City of medicine hat concentrating solar thermal demonstration project, alberta, canada. Energy Procedia 49, 1792-1799.

URL http://dx.doi.org/10.1016/j.egypro.2014.03.190

MATLAB, 2014. version 8.3 (R2014a). The MathWorks Inc., Natick, Massachusetts.

Medrano, M., Gil, A., Martorell, I., Potau, X., Cabeza, L. F., 2010. State of the art on high-temperature thermal energy storage for power generation. part 2a: Case studies. Renewable and Sustainable Energy Reviews 14 (1), $56-72$.

NASA Langley Atmospheric Sciences Data Center, 2008. Solar: Average Monthly and Annual Direct Normal Irradiance Data, One-Degree Resolution of the World from NASA/SSE, 1983-2005. NASA Available at: http://purl.stanford.edu/fd535zg0917.

National Renewable Energy Laboratory (NREL), 2012. Cost and performance data for power generation technologies. Tech. rep., prepared by Black \& Veatch.

URL http://bv.com/docs/reports-studies/nrel-cost-report.pdf

National Renewable Energy Laboratory (NREL), 2015. National Solar Radiation Data Base. [Online]. Available at: http://rredc.nrel.gov/solar/old_data/nsrdb/, Accessed 30 April 2014.

National Renewable Energy Laboratory, NREL, 2016a. Concentrating Solar Power Projects - City of Medicine Hat ISCC Project. http://www.nrel.gov/csp/solarpaces/project_detail.cfm/projectID= 278, Accessed: 2016-06-25.

National Renewable Energy Laboratory, NREL, 2016b. Concentrating Solar Power Projects - Gemasolar Thermosolar Plant. http://www.nrel.gov/csp/solarpaces/project_detail.cfm/projectID=40, Accessed: 2016-06-25.

National Renewable Energy Laboratory, NREL, 2016c. Concentrating Solar Power Projects by Country. http://www.nrel.gov/csp/solarpaces/by_country.cfm, Accessed: 2016-06-31.

Natural Resources Canada, 2013. Improving energy performance in canada: Report to parliament under the energy efficiency act for the fiscal year 2012-2013. Tech. rep., Government of Canada.

Nielsen, S., 10 February 2011. A Solar Mother Lode for Chile's Mines. Businessweek, [Online]. Available at: http://www . businessweek.com/magazine/content/11_08/b4216012473761.htm (Accessed 06 September 2014).

Notton, G., Lazarov, V., Stoyanov, L., Feb 2010. Optimal sizing of a grid-connected PV system for various PV module technologies and inclinations, inverter efficiency characteristics and locations. Renewable Energy $35(2), 541-554$.

Ortega, J. I., Burgaleta, J. I., Tellez, F. M., 2008. Central receiver system solar power plant using molten salt as heat transfer fluid. Journal of Solar Energy Engineering 130 (2), 024501. 
Osborn, J., Kawann, C., 2001. Reliability of the US Electricity System: Recent Trends and Current Issues. Energy Analysis Department, Ernest Orlando Lawrence Berkeley National Laboratory, LBNL-47043, Berkeley, CA.

Ould Bilal, B., Sambou, V., Ndiaye, P., Kebe, C., Ndongo, M., Oct 2010. Optimal design of a hybrid solarwind-battery system using the minimization of the annualized cost system and the minimization of the loss of power supply probability (lpsp). Renewable Energy 35 (10), 2388-2390.

URL http://dx.doi.org/10.1016/j.renene.2010.03.004

Paatero, J. V., Lund, P. D., Feb 2007. Effects of large-scale photovoltaic power integration on electricity distribution networks. Renewable Energy 32 (2), 216-234.

Paraszczak, J., Fytas, K., 23-30 Mar 2012. Renewable energy sources - a promising opportunity for remote mine sites? In: International Conference on Renewable Energies and Power Quality (ICREPQ 12). Santiago de Compostela (Spain).

Pearson, K., 1916. Mathematical contributions to the theory of evolution. xix. second supplement to a memoir on skew variation. Philosophical Transactions of the Royal Society of London A: Mathematical, Physical and Engineering Sciences 216 (538-548), 429-457.

Pellegrino, J., Margolis, N., Justiniano, M., Miller, M., Thedki, A., 2004. Energy use, loss and opportunities analysis: Us manufacturing and mining. US Department of Energy.

Relloso, S., Delgado, E., Sept 2009. Experience with molten salt thermal storage in a commercial parabolic trough plant; andasol 1 commissioning and operation. In: Proceedings of 15 th International SolarPACES Symposium. pp. 14-18.

Sasitharanuwat, A., Rakwichian, W., Ketjoy, N., Yammen, S., Jul 2007. Performance evaluation of a 10kwp PV power system prototype for isolated building in thailand. Renewable Energy 32 (8), 1288-1300.

Tawarmalani, M., Sahinidis, N. V., May 2005. A polyhedral branch-and-cut approach to global optimization. Math. Program. 103 (2), 225-249.

Tina, G., Gagliano, S., Raiti, S., May 2006. Hybrid solar/wind power system probabilistic modelling for long-term performance assessment. Solar Energy 80 (5), 578-588.

Tudorache, T., Morega, A., 2008. Optimum design of wind/pv/diesel/batteries hybrid systems. In: Second International Conference on Modern Power Systems, Romania.

Wagner, M., Gilman, P., 2011. Technical Manual for the SAM Physical Trough Model. Tech. rep., National Renewable Energy Laboratory (NREL), Golden, CO.

Widen, J., Carpman, N., Castellucci, V., Lingfors, D., Olauson, J., Remouit, F., Bergkvist, M., Grabbe, M., Waters, R., Apr 2015. Variability assessment and forecasting of renewables: A review for solar, wind, wave and tidal resources. Renewable and Sustainable Energy Reviews 44, 356-375.

Wong, L., Chow, W., Jul 2001. Solar radiation model. Applied Energy 69 (3), 191-224.

Yang, H., Lu, L., Burnett, J., 2003. Weather data and probability analysis of hybrid photovoltaic-wind power generation systems in hong kong. Renewable Energy 28 (11), 1813 - 1824.

Yang, H., Lu, L., Zhou, W., Jan 2007. A novel optimization sizing model for hybrid solar-wind power generation system. Solar Energy 81 (1), 76-84.

URL http://dx.doi.org/10.1016/j.solener.2006.06.010

Yang, H., Wei, Z., Chengzhi, L., Feb 2009. Optimal design and techno-economic analysis of a hybrid solarwind power generation system. Applied Energy 86 (2), 163-169.

Yang, H., Zhou, W., Lu, L., Fang, Z., Apr. 2008. Optimal sizing method for stand-alone hybrid solar-wind system with lpsp technology by using genetic algorithm. Solar Energy 82 (4), 354-367.

URL http://www.sciencedirect.com/science/article/pii/S0038092X07001831 
Zaversky, F., Garcia-Barberena, J., Sanchez, M., Astrain, D., 2013. Transient molten salt two-tank thermal storage modeling for CSP performance simulations. Solar Energy 93 (0), $294-311$.

Zunft, S., Jakiel, C., Koller, M., Bullough, C., 26.28 October 2006. Adiabatic compressed air energy storage for the grid integration of wind power. In: Proceedings of the sixth international workshop on large-scale integration of wind power and transmission networks for offshore windfarms. 


\section{AppendixA. Dynamic models for energy system}

Dynamic models describe the behaviour and changing states of the energy generation and storage systems. The models rely on the direct normal irradiance (DNI), $\dot{G}^{D N I}(t)\left[\mathrm{W} \cdot \mathrm{m}^{-2}\right]$, and global horizontal irradiance $(\mathrm{GHI}), \dot{G}^{t o t}(t)\left[\mathrm{W} \cdot \mathrm{m}^{-2}\right]$, which are estimated from historical instantaneous GHI data, as detailed below (section $\S 5)$. The equations described below are valid over the entire time interval of operation $t \in\left[0, t_{\text {final }}\right]$.In the equations presented below, $C$ represents the capacities of units, $\dot{E}, \dot{Q}$ and $\dot{D}$ represent electricity, heat and demand rates [MW], while $S$ represents stored energy [MWh]. Subscript $i$ refers to energy generation options (PV, PT) and $j$ for the storage options (PHES, AA-CAES, MTS). Superscripts gen, s, in, out, el and $t h$ represent generation, storage, input, output, electrical and thermal respectively. Other notation used is described when introduced.

\section{AppendixA.1. Generation models}

The rate of electricity production, $\dot{E}_{P V}^{\text {gen }}[\mathrm{MW}]$, of an installed $\mathrm{PV}$ array of area $A_{p}\left[\mathrm{~m}^{2}\right]$ is given by

$$
\dot{E}_{P V}^{g e n}(t)=\eta_{p v}(t) \eta_{i n v} A_{p} \dot{G}^{t o t}(t)
$$

where $\eta_{i n v}$ is the inverter efficiency. The solar module efficiency $\eta_{p v}$ is dependent on temperature and solar irradiance and is given by the Evans model (Evans, 1981; Notton et al., 2010) as

$$
\eta_{p v}(t)=0.1244\left[1-0.0048\left(T_{\text {cell }}(t)-25\right)+0.12 \log \left(\frac{\dot{G}^{\text {tot }}(t)}{1000}\right)\right]
$$

for silicon solar cells.

Power towers convert solar to thermal energy. The rate of thermal energy generation by a power tower with an installed collector of area $A_{c}\left[\mathrm{~m}^{2}\right]$ is

$$
\dot{Q}_{P T}^{g e n}(t)=\alpha \eta_{h e l} A_{c} \dot{G}^{D N I}(t)-\left(\dot{Q}^{\text {conv }}(t)+\dot{Q}^{\text {rad }}(t)\right)
$$

where $\dot{Q}^{\text {conv }}(t)$ and $\dot{Q}^{\text {rad }}(t)$ are the rates of heat losses from the receiver via convection and radiation [MW] respectively; $\alpha$ the absorptivity; and $\eta^{\text {hel }}$ the efficiency of the heliostat reflectors.

Often in power systems, generation exceeds the amount of energy that can be used and stored. The excess energy must therefore be dissipated in some way. This process is called energy dumping. For concentrated solar power (CSP) technologies, energy dumping occurs when the MTS capacity is reached (Kueh et al., 2015) and is achieved by defocusing the collectors (heliostats) thereby reducing the amount of energy that reaches the power tower (Wagner and Gilman, 2011). The amount of energy not collected for storage is called dumped thermal energy. Thus, the actual energy transferred to the salt $\dot{Q}_{M T S}^{\text {in }}(t)$ may be less than the potential generation from the power tower,

$$
\dot{Q}_{M T S}^{i n} \leq \dot{Q}_{P T}^{\text {gen }}(t)
$$

Based on the installed areas, $A_{p}$ and $A_{c}$, the nominal capacities $\left(C_{i}^{g e n}\right)$ may be calculated. The nominal capacities are the energy outputs of each generation technology under ideal solar input conditions. Design irradiances of $1 \mathrm{~kW} \cdot \mathrm{m}^{-2}$ for GHI (irradiance level under standard test conditions for PV modules) and $0.95 \mathrm{~kW} \cdot \mathrm{m}^{-2}$ for DNI (NREL, 2012) are used in this work to estimate these capacities. The energy generated will depend on the actual irradiances which will vary continuously. It is the impact of this difference between nominal capacity and actual generation on the designs generated that is investigated in this paper. 


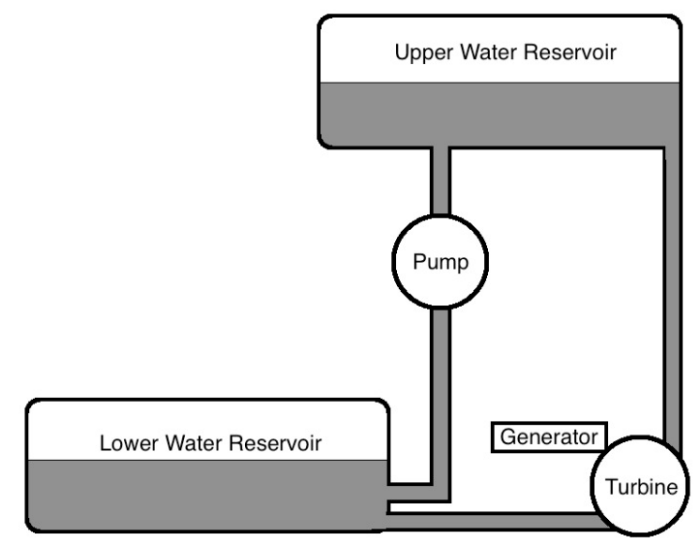

Figure A.11: Schematic representation of a double penstock PHES system. The system incorporates two penstocks (separate pump and turbine) to ensure that charging and discharging can occur simultaneously. Source: Blonbou et al., 2013

\section{AppendixA.2. Storage models}

An energy balance around the PV system (Figure 1) yields

$$
\dot{E}_{P V}^{g e n}(t)=\dot{E}^{d}(t)+\dot{E}_{\text {store }}^{\text {in }}(t)
$$

$\dot{E}^{d}(t)$ is the electricity generated which does not go through storage. It is made up of two components: electricity supplied directly to the process for operation and electricity that is dumped due to excess generation. For the PV system, dumping is achieved using a load diverting regulator which diverts the excess electricity to an alternate (dump) load such as a water heater (Sasitharanuwat et al., 2007; Tudorache and Morega, 2008). $\dot{E}_{\text {store }}^{\text {in }}$ is the electrical energy sent to the storage systems. This energy is directed to one of two storage systems and the fraction going to the PHES system is $f$ with the remainder going to the AA-CAES system:

$$
\begin{gathered}
\dot{E}_{P H E S}^{\text {in }}(t)=f \cdot \dot{E}_{\text {store }}^{\text {in }}(t) \\
\dot{E}_{A A-C A E S}^{\text {in }}(t)=(1-f) \cdot \dot{E}_{\text {store }}^{\text {in }}(t)
\end{gathered}
$$

AppendixA.2.1. Pumped hydro energy storage (PHES) system

The fundamental principle of pumped hydraulic energy storage (PHES) is to store excess electrical energy in the form of gravitational potential energy. Figure A.11 shows the schematic of a typical PHES system. During periods of low demand or excess generation, available electricity is used to pump water to an upper reservoir. During times of high demand, water is released from the upper reservoir to power a turbine. With a response time of seconds, the technology is currently the most used for high-power applications, representing over $99 \%$ of installed large scale energy storage (International Energy Agency, 2014).

For a reservoir height difference $h$, the energy rate to the store during the charging phase $\left(\dot{E}_{P H E S}^{\text {in }}(t)\right)$ and water flowrate $\dot{m}_{P H E S}^{i n}(t)\left[\mathrm{kg} \cdot \mathrm{s}^{-1}\right]$ pumped to the upper reservoir are related by the expression

$$
\eta_{p u m p} \dot{E}_{P H E S}^{\text {in }}(t)=g h \cdot \dot{m}_{P H E S}^{\text {in }}(t)
$$

where $\eta^{\text {pump }}$ is the pump efficiency. There is a similar expression for the electrical output of the turbine during discharge, taking into account the turbine losses $\eta^{\text {tur }}$ :

$$
\dot{E}_{P H E S}^{\text {out }}(t)=\eta^{\text {tur }} g h \cdot \dot{m}_{P H E S}^{\text {out }}(t)
$$




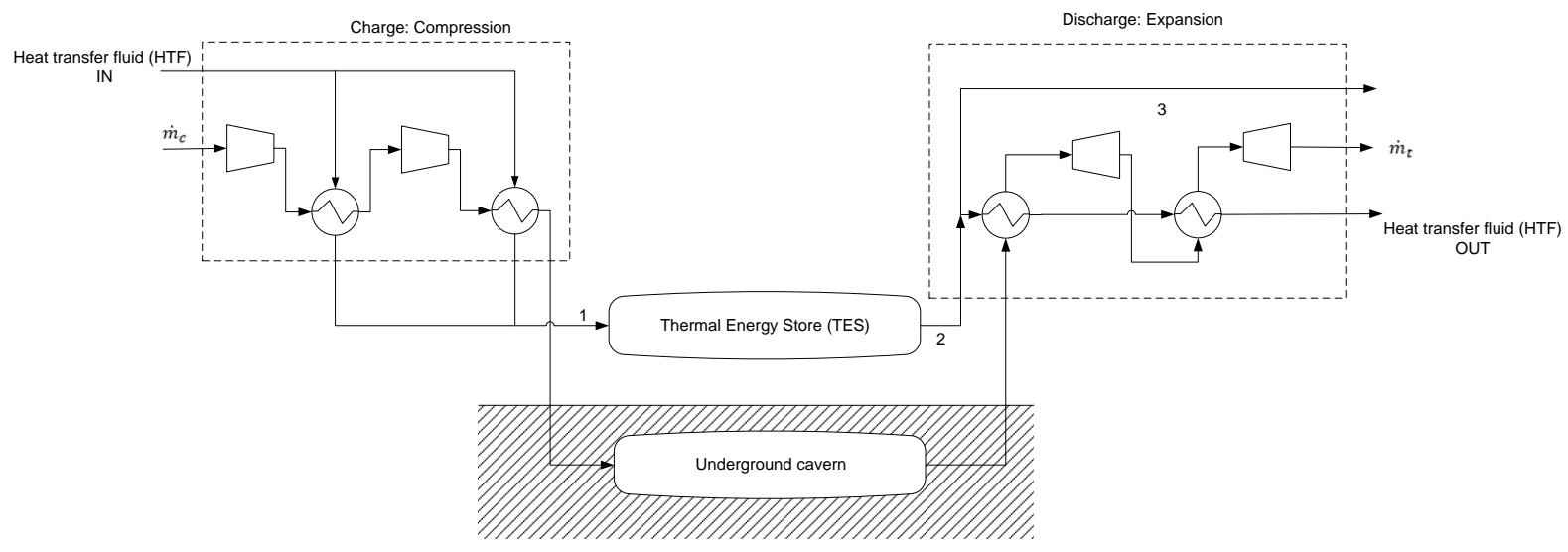

Figure A.12: Schematic diagram of the modelled AA-CAES system showing the charging and discharging phases. Streams 1 and 2 are material streams which carry heat into and out of the heat store. Stream 3 supplies thermal energy to the plant

The difference in the instantaneous flowrates of water into and out of around the upper water reservoir gives the rate of change of water accumulated in the reservoir:

$$
\frac{\mathrm{d}}{\mathrm{d} t} m_{P H E S}^{s}(t)=\dot{m}_{P H E S}^{\text {in }}(t)-\dot{m}_{P H E S}^{\text {out }}(t)
$$

The rate of change of the energy stored in the PHES system is then

$$
\frac{\mathrm{d}}{\mathrm{d} t} S_{P H E S}(t)=g h \frac{\mathrm{d}}{\mathrm{d} t} m_{P H E S}^{s}(t)
$$

\section{AppendixA.2.2. Advanced Adiabatic Compressed Air Energy Storage (AA-CAES) system}

The AA-CAES system stores potential energy, in the form of high pressure air, as well as heat in a thermal energy store (Figure A.12). During the charging phase, inlet air is polytropically compressed in two stages, with heat removed after each stage. Electricity generation also occurs in two polytropic stages, with preheating before each air expansion stage. Constant-pressure air storage is adopted (Kim et al., 2012). Thermal energy for process heating can be withdrawn from the system after compression and/or before expansion.

The rate of energy input for compression during charging is given by

$$
\eta^{\text {comp }} \eta^{\text {motor }} \dot{E}_{A A-C A E S}^{\text {in }}(t)=\frac{n}{n-1} \dot{m}_{c}(t) \cdot R_{A} \sum_{c=1}^{N_{c}} \Delta T^{c}
$$

where $n$ is the polytropic exponent, $\dot{m}_{c}\left[\mathrm{~kg} \cdot \mathrm{s}^{-1}\right]$ is the air flowrate into the compressor $c$ during charging, $\triangle T^{c}$ is the temperature difference between the compressor's inlet and outlet $[\mathrm{K}], R_{A}$ is the specific gas constant for air $\left[287 \mathrm{~J} \cdot \mathrm{kg}^{-1} \cdot \mathrm{K}^{-1}\right], \eta^{\text {comp }}$ is the compressor efficiency, $\eta^{\text {motor }}$ the motor efficiency and $N_{c}$ the number of compressors. Grazzini and Milazzo (2012) and Hartmann et al. (2012) give the relationship between the polytropic exponent and the mechanical efficiencies of turbines and compressors as

$$
\eta^{\text {comp }}=\frac{n}{n-1} \cdot \frac{\gamma-1}{\gamma}=\frac{1}{\eta^{\text {turbine }}}
$$

where $\gamma$ is the specific heat ratio.

A similar expression to Eq. (A.12) may be written for the electrical output from the turbines during discharge, $E_{A A-C A E S}^{o u t}(t)$, taking into account the generator and turbine losses:

$$
\frac{1}{\eta^{\text {gen }} \eta^{\text {turbine }}} \dot{E}_{A A-C A E S}^{\text {out }}(t)=\frac{n}{n-1} \dot{m}_{t}^{c}(t) \cdot R_{A} \sum_{t=1}^{N_{t}} \Delta T^{\text {turbine }}
$$




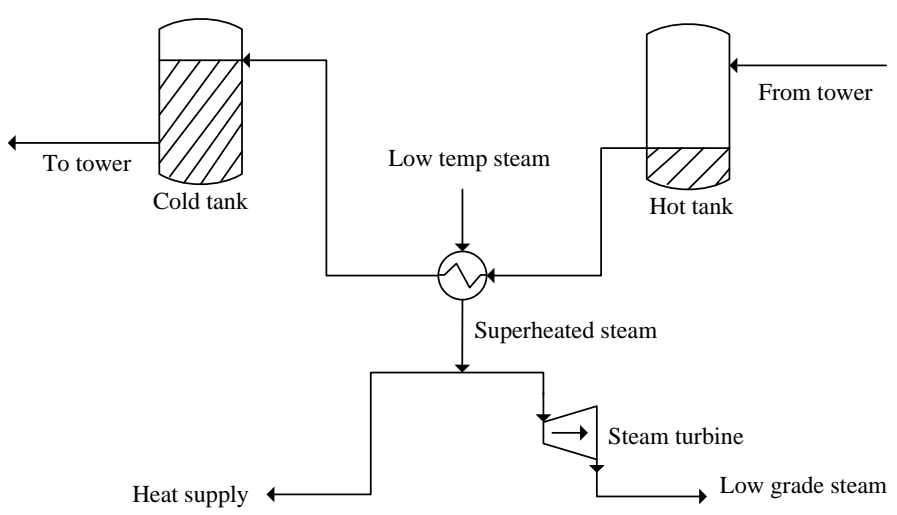

Figure A.13: Schematic representation of molten salt storage system

where $\dot{m}_{t}(t)$ is the air flowrate into the turbine $\left[\mathrm{kg} \cdot \mathrm{s}^{-1}\right], \eta^{\text {turbine }}$ is the turbine efficiency, $\eta^{\text {gen }}$ the generator efficiency and $\Delta T^{\text {turbine }}$ is the difference in inlet and outlet operating temperatures of the turbines $[\mathrm{K}]$.

The difference in the instantaneous flowrates of air in and out of cavern gives the rate of change of pressurized air. For a stored mass of air $m_{A A-C A E S}^{s}(t)[\mathrm{kg}]$ :

$$
\frac{\mathrm{d}}{\mathrm{d} t} m_{A A-C A E S}^{s}(t)=\dot{m}_{c}(t)-\dot{m}_{t}(t)
$$

The use of thermal energy storage in solid media is motivated by Zunft et al. (2006) which suggests solid storage as the most technologically favourable thermal storage option for integration into AA-CAES systems. An energy balance around the thermal energy store (TES) gives an expression for the temperature of the TES, $T^{T E S}(t)$, as a function of the heat flow rates in, $\dot{Q}^{T E S, i n}(t)$, and out, $\dot{Q}^{T E S, o u t}(t)$ :

$$
\rho c_{p} V_{s} \frac{\mathrm{d}}{\mathrm{d} t} T^{T E S}(t)=\left[\dot{Q}^{T E S, \text { in }}(t)-\dot{Q}^{T E S, \text { out }}(t)-\dot{Q}^{\text {TES,loss }}(t)\right]
$$

The energy balance on the TES takes into account the thermal losses from the heat store. The temperature of the TES is limited by the maximum operating temperature of the storage media:

$$
T^{T E S}(t) \leq T_{\max }^{T E S}
$$

The energy accumulated within the system is calculated based on the mass holdup in the cavern and the operating conditions of the turbines,

$$
\frac{\mathrm{d}}{\mathrm{d} t} S_{A A-C A E S}(t)=\frac{n}{n-1} R_{A} \sum_{N_{t}} \triangle T^{t u r b i n e} \cdot \frac{\mathrm{d}}{\mathrm{d} t} m_{A A-C A E S}^{s}(t)
$$

\section{AppendixA.2.3. Two-tank molten salt storage system}

In molten salt thermal storage, energy is stored in the form of sensible heat. Thermal energy generated from the power tower is collected by salt from the cold tank and sent to the hot tank for storage. When energy is required, salt from the hot tank exchanges heat with low temperature steam to produce high temperature steam to meet the plant's thermal demands directly or to power a steam turbine for electricity generation. The molten salts therefore act as both the heat transfer fluid for the power tower and a heat storage medium, as shown in Figure A.13. This work considers two cylindrical tanks fitted with electrical heaters and maintained at fixed storage temperatures, as described in Medrano et al. (2010).

The enthalpy accumulated, $H_{s, t}^{a c c}$, in tank $\mathrm{s}(s=\{C T, H T\})$ at any time is given by

$$
\frac{\mathrm{d}}{\mathrm{d} t} H_{s}^{a c c}(t)=\dot{H}_{s}^{\text {in }}(t)-\dot{H}_{s}^{\text {out }}(t)-\dot{Q}_{s}^{\text {loss }}(t)+\dot{E}_{s}^{h}(t) \quad \forall s
$$


where $\dot{H}_{s}^{\text {in }}(t), H_{s}^{\text {out }}(t), \dot{Q}_{s}^{\text {loss }}(t)$ and $\dot{E}_{s}^{h}(t)$ refer to rates of enthalpy addition [W], enthalpy removal [W], heat loss from the tank [W] and heat addition to tank via the heater [W] respectively. The electrical heating of the tank $\dot{E}_{s}^{h}(t)$ is required to maintain the tank temperature above the solidification temperature of the salt. This is key, especially if the system is to be used intermittently. An empirical heat loss expression including both the temperature difference between the salt in the tank and ambient air $\left(\Delta T_{s}\right)$ and the salt fill level of the tank $\left(\chi_{s}\right)$ has been derived:

$$
\dot{Q}_{s}^{\text {loss }}(t)=U_{s}^{\text {loss }} A_{\text {tank }} \Delta T_{s} \cdot \chi_{s}(t)^{p}
$$

where $U_{s}^{\text {loss }}$ and $A_{\text {tank }}$ are the overall heat loss coefficient $\left[\mathrm{Wm}^{-2} \mathrm{~K}^{-1}\right]$ and area of the storage tank $\left[\mathrm{m}^{2}\right]$ respectively. The value of the exponential term $(p)$ was calculated based on recorded plant data for the Andasol-1 plant (Relloso and Delgado, 2009), with the exponent obtained as 0.3 when data from both the hot and cold tanks were used. This indicates that the exponent is independent of temperature which is important since Andasol-1 is operated at lower temperatures for a parabolic trough plant. The overall heat loss coefficient for each of the tanks was then estimated with Eq. (A.20) based on data recorded at the Solar-Two test project (Bradshaw et al., 2002), a plant incorporating direct salt storage at similar operating temperatures. This yielded the overall heat loss coefficients as $0.335 \mathrm{Wm}^{-2} \mathrm{~K}^{-1}$ and $0.364 \mathrm{Wm}^{-2} \mathrm{~K}^{-1}$ for the cold and hot tanks respectively.

The operating temperature range of the salt is determined by the salt solidification and decomposition temperatures, as given in Zaversky et al. (2013). The salt solidification temperature was also set as the reference temperature for the system.

Since only energy in the hot tank may supply the plant, the rate of change of stored thermal energy is the same as the rate of enthalpy accumulation in the hot tank,

$$
\frac{\mathrm{d}}{\mathrm{d} t} S_{M T S}(t)=\frac{\mathrm{d}}{\mathrm{d} t} H_{H T}^{a c c}(t)
$$

The electricity supplied to the plant from the molten salt tank system is given by the electricity generated from the hot tank output stream less the energy removed for heating $\dot{Q}_{M T S}^{\text {heating }}(t)$ :

$$
\dot{E}_{M T S}^{\text {out }}(t)=\eta^{s t}\left[\dot{H}_{H T}^{\text {out }}(t)-\dot{Q}_{M T S}^{\text {heating }}(t)\right]
$$

where $\dot{H}_{h t}^{\text {out }}(t)$ is the heat out of the hot tank [W] and $\eta^{s t}$ is steam turbine's thermal-to-electrical energy conversion efficiency.

\section{AppendixA.3. Optimization model constraints}

In addition to the dynamic models related to the behaviour of the generation and storage units presented in the previous section, several physical constraints are placed on the model so that it may be used for generating designs.

\section{AppendixA.3.1. Capacity constraints}

For each storage option, the energy accumulated at any point during operation cannot be greater than the installed storage capacity. Similarly, the instantaneous electrical output from any storage option cannot exceed the installed capacity of the delivery unit (turbine):

$$
\begin{gathered}
S_{j}(t) \leq C_{j}^{s} \quad \forall j \\
\dot{E}_{j}^{\text {out }}(t) \leq C_{j}^{\text {out }} \quad \forall j
\end{gathered}
$$




\section{AppendixA.3.2. Constraints enforcing demand satisfaction}

For off-grid operation of the mine, the process demands of the plant must be met by the integrated energy system (Figure 1). The electricity supplied by the energy system must be sufficient to meet both the electrical demands of the plant and the electrical heating requirements of the molten salt tanks,

$$
\dot{D}^{e l}(t) \leq \dot{E}^{d}(t)+\sum_{j=1}^{3} \dot{E}_{j}^{\text {out }}(t)-\sum_{s} \dot{E}_{s}^{h}(t)
$$

The inequality sign accounts for any energy dumping that may be required due to excess generation by the PV system.

The thermal requirements of the plant must be met from either the AA-CAES or molten salt system,

$$
\dot{D}^{\text {th }}(t) \leq \dot{Q}_{A A-C A E S}^{\text {heating }}(t)+\dot{Q}_{M T S}^{\text {heating }}(t)
$$

The heat from the storage systems can be used for mild-temperature applications such as space heating, fluid heating and steam generation, all of which would be useful applications in remote mines and beneficiation plants (Eglinton et al., 2013). Other storage options would be required for applications requiring higher temperatures.

\section{AppendixA.3.3. Boundary value constraints}

The problem described so far is an initial value problem. Attempting to solve this problem without further constraints may generate designs with large differences in the amounts of energy stored at the start and at the end of the process. This is because objective function is dependent on the capacities of the units installed; energy available at the start of the process is not costed. Thus, the optimal solution involves having a large amount of "free" energy at the start of the process, thereby reducing the need to generate such energy. In practice, the design is unrealistic as it means the plant would eventually require external energy to resume operation. In order to avoid this, the problem is converted to a boundary value problem by imposing equality constraints on the endpoints of the system: the initial and final states of each storage options is the same, meaning that no net energy changes occur over the period of operation.

Constraints are also placed on the independent variables that determine the state of the storage systems. For the PHES system, a constraint was placed on the volume of water in the upper reservoir. For the molten salt system, a constraint was placed on the mass of salt accumulated in the hot tank. For the AA-CAES system, both the mass of air in the cavern and the temperature of the thermal store were constrained:

$$
\begin{aligned}
m_{A A-C A E S}^{s}(0) & =m_{A A-C A E S}^{s}\left(t_{\text {final }}\right) \\
T^{T E S}(0) & =T^{T E S}\left(t_{\text {final }}\right)
\end{aligned}
$$

\section{AppendixA.4. Model discretization}

The dynamic models were discretized using Euler's backward differencing technique with a uniform time step $\Delta t$, converting the differential-algebraic system of equations to a fully algebraic system of equations. The time horizon, $t \in\left[0, t_{\text {final }}\right]$, is discretised into $n_{t}$ intervals, $\Delta t=\frac{t_{\text {final }}}{n_{t}}$. We introduce $\tau=0, \ldots, n_{t}$ as an index into the discretised time interval. All time dependent continuous variables in the model are replaced by corresponding time-step indexed discrete terms. For example, Equation (A.19) becomes:

$$
H_{s, \tau}^{a c c}-\Delta t\left[\dot{H}_{s, \tau}^{\text {in }}-\dot{H}_{s, \tau}^{\text {out }}-\dot{Q}_{s, \tau}^{\text {loss }}+\dot{E}_{s, \tau}^{h}\right]=H_{s, \tau-1}^{a c c} \quad s ; \tau=1, \ldots, n_{t}
$$

From this point onwards, equations relating to the model are presented in discrete form.

The discretization of the model, when combined with the incorporation of boundary value constraints, increases the complexity of the problem. This is because the algebraic system that results from discretisation needs to be solved simultaneously for all time steps $\tau$. 


\section{AppendixB. Cost comparison with diesel generation}

To obtain the true cost of diesel generation, we compute the cost of diesel generation over 20 years (the typical lifetime of a mine).

Al-Shamma'a and Addoweesh (2014) gives the equation for annual diesel cost in L/year as:

$$
F(t)=C_{F} \sum_{t=1}^{8760}\left[246 \cdot D^{e l}(t)+84.5 \cdot P_{R}\right]
$$

where $D^{e l}$ is the hourly demand of the plant [MWh], $P_{R}$ is the rated capacity of the diesel generator [MWh], and $C_{F}$ the unit cost of diesel per litre. For one year of with an average demand of $171 \mathrm{MWh}$, peak demand of $178 \mathrm{MWh}$ and diesel unit cost of $\$ 0.72 / \mathrm{L}$ (current diesel cost in Canada), the annual cost of diesel required to run the plant is $\$ 360.2 \mathrm{M}$. Over 20 years, the total cost spent on diesel purchase is $\$ 7.203$ billion (€6.7 billion). This is without considering the cost of diesel generator purchase ( $\$ 308.5 \mathrm{M}$ for $180 \mathrm{MW}$ output based on a unit cost of $\$ 857 / \mathrm{kW}$ and 10 years of service (Al-Shamma'a and Addoweesh, 2014)), potential diesel cost fluctuations and the cost of the greenhouse emissions associated with diesel generation.

Thus, while the capital cost required for renewables generation is high compared to diesel generation, the costs of renewables and diesel generation are comparable over the lifetime of the mine. 